\title{
Possible correlation between the vertical component of lithospheric magnetic field and continental seismicity
}

\author{
Yu Lei, Liguo Jiao* (10) and Huaran Chen
}

\begin{abstract}
Recent magnetic satellite missions facilitate new birth of large-scale geomagnetic field models and their applications to tectonics. Here, we directly compare the global geomagnetic field models NGDC-720 with the tectonics and seismicity in Mainland China and surroundings. It is found that the tectonics and seismicity in this area show remarkable correlation with the vertical component of lithospheric magnetic field $\left(B_{z}\right)$ calculated at an altitude of $200 \mathrm{~km}$. Previous thought was that earthquakes are more likely to occur in zero $B_{z}$ belts or in obvious anomaly gradient belts. On the contrary, we find that more than half (53.2\%) of the earthquakes occurred in areas with $B_{z}$ of -5 to $-3 \mathrm{nT}$ or in areas with a relatively small horizontal gradient of $B_{z}$ in the same time interval with the satellite data. The percentage seismic energy in these areas ( $\left.-5 \mathrm{nT}<B_{z}<-3 \mathrm{nT}\right)$ is even as high as $94.6 \%$. We explain this unexpected result with a two equivalent source dipole model, arguing that the viscosity difference caused by the temperature gradient within the lithosphere likely accounts for the correlation between magnetic anomalies and seismicity.
\end{abstract}

Keywords: Lithosphere magnetic field, Satellite, Tectonics, Continental seismicity, Mainland China

\section{Introduction}

From 1999 to 2009, three magnetic satellites, Ørsted, SAC-C, and CHAMP, were launched along with gravitational satellites (including CHAMP), causing Christensen et al. (2009) to call this period the geopotential decade. New global lithospheric magnetic field (LMF) models were built by combining satellite observations with ground, marine and airborne data. These models include CM1-4 (Sabaka et al. 2004), MF1-7 (Maus et al. 2008), EMAG2-3 (Maus et al. 2009), and NGDC-720 (Maus 2010), Langel and Hinze (1998) provided a comprehensive overview of satellite LMF modeling, and Thébault et al. (2010) summarized these LMF models. After November 22, 2013, the launch of SWARM constellation, even more geomagnetic models were built or updated (Olsen et al. 2016). Because global and regional LMF models are valuable for plate tectonics and lithospheric dynamics, these new satellite observations and new

\footnotetext{
*Correspondence: Igjiao@cea-igp.ac.cn

Institute of Geophysics, China Earthquake Administration, Beijing 100081, China
}

models provide unprecedented opportunities to study the correlation between LMF and tectonics, furthermore seismicity on a large regional scale.

Earthquake occurrence is complex and nonlinear. Although timing is hard to predict, location does follow a few rules: Most middle and large earthquakes occur along boundaries of plates (Beroza and Kanamori 2007), or along boundaries of active tectonic blocks (Zhang et al. 2003, 2005). Seismicity also correlates with other geophysical parameters, such as lithospheric thickness (Chen et al. 2013), gravity field (Zhang et al. 2010; Mitsui and Yamada 2017), and aeromagnetic anomalies (Zhang et al. 2010). A common feature is that large earthquakes tend to occur along the remarkable gradient belts of these parameters.

The correlation between earthquakes and magnetic anomalies has been noticed for some time (Johnston 1997; Han et al. 2009; Huang 2011; Zhang et al. 2013; Marianna et al. 2014). Although authors have examined the temporal variation of magnetic anomalies near the epicenter before and after some large earthquakes, studies of the correlation between seismicity and magnetic 
anomalies are rare. An important hindrance to such studies has been that most geomagnetic data were obtained from ground-based observations. These observations face two difficulties: removing disturbances of near-surface magnetic sources and reducing all data to the same period. Either factor may introduce errors even stronger than the earthquake-related signals themselves. By avoiding the difficulties of near-surface data, satellite observations provide a better description of large-scale magnetic profile, making them more suitable for studying regional tectonics and seismicity. Taking advantage of the rapid development of satellite magnetic observations, several recent studies have applied these observations to earthquakes (Taylor et al. 2008; von Frese et al. 2008).

China lies at the junction of three tectonic plates: India, Pacific and Eurasia. Tremendous topographic contrasts combine with abnormally active tectonics to give China complex geography and serious seismic hazards. Previous studies (Deng et al. 2002; Zhang et al. 2003) have shown that plates in this area move as active, cohesive blocks. Different tectonic units (blocks, basins, orogens, faults, etc.) may exhibit diverse LMF characteristics. These factors make China and surroundings suitable and unique for studying the correlation between LMF and seismicity. Figure 1 presents the topography (ETOPO1), plate boundaries (UTIG), active blocks (Zhang et al. 2003), and GPS movements (Wang et al. 2001) in our research area $\left(\mathrm{E} 72^{\circ}-136^{\circ}, \mathrm{N} 16^{\circ}-56^{\circ}\right)$.

The distribution of satellite LMF in China has been studied for more than 20 years. As early as the MAGSAT era, An et al. (1992) studied the magnetic anomaly of China and its adjacent region with spherical cap harmonic analysis. Xu (1997) and Xu et al. (2000) calculated the apparent magnetization of Mainland China and compared it with geology and heat flux. Alsdorf and Nelson (1999) hypothesized that the negative

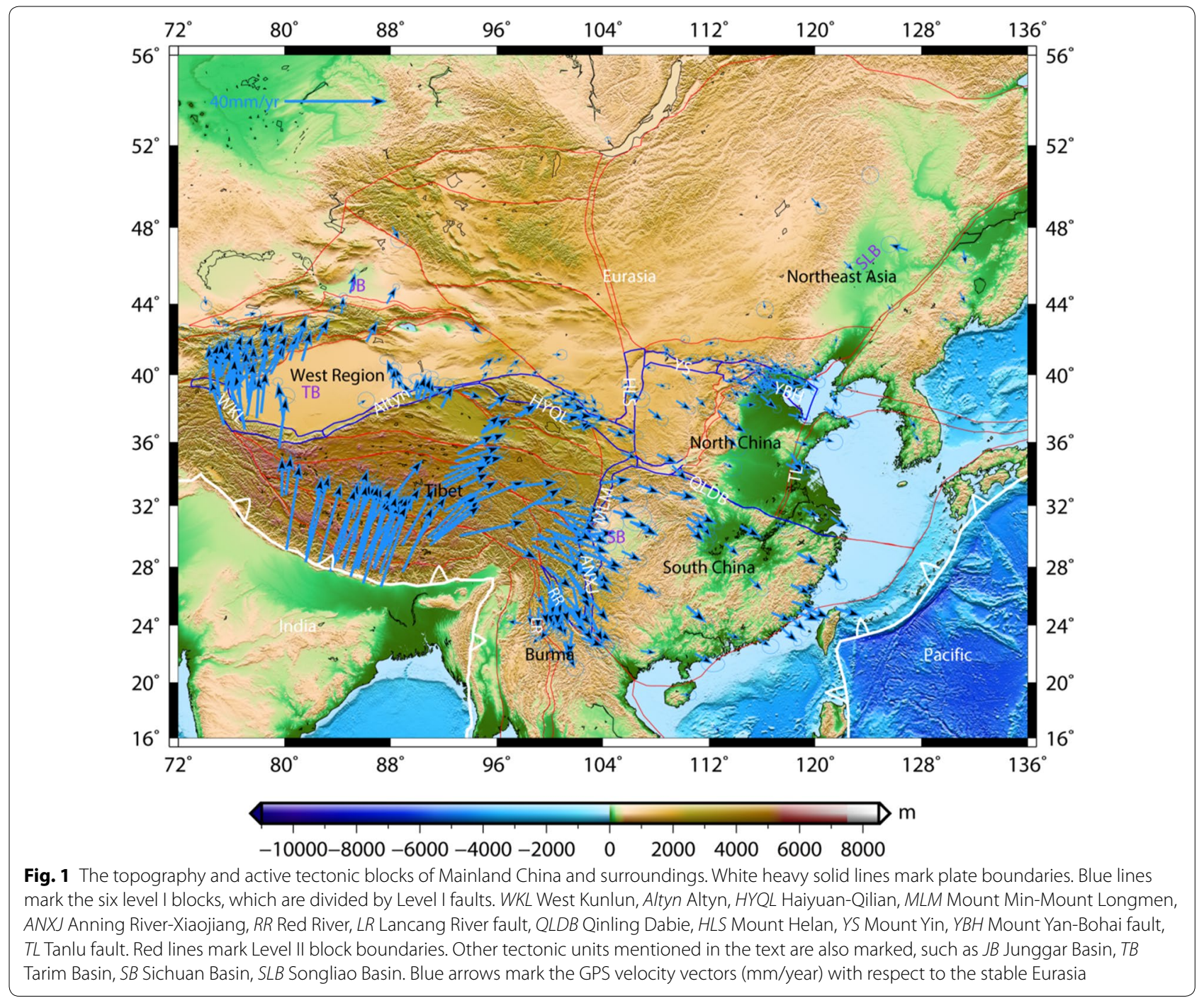


anomaly of the Tibetan plateau results from a widespread melt crust. After CHAMP, Wang et al. (2008) and Kang et al. (2010) discussed the distributions of new global LMF models in China. Kang et al. (2010) found a positive correlation between LMF and the Curie depth. Using NGDC-720 model, they analyzed the crustal magnetic anomalies of the Tibetan plateau. Kang et al. (2013) used wavelet analysis to study the magnetic anomaly distribution and its attenuation with altitude around the eastern Himalayan syntaxis. Their research revealed that the magnetic anomaly boundaries agree well with the borders of the plateau regional tectonics.

These studies further verified the validity of satellite magnetic observations and the correspondence between LMF and tectonic features. Few studies, however, use the new magnetic satellite data or the new LMF models to examine the correlation between satellite LMF and seismicity. Taylor et al. (2008) compared the CHAMP scalar magnetic anomalies at an altitude of $350 \mathrm{~km}$ with the seismicity of the Korean Peninsula. They found that the zero contour of magnetic anomaly divides the seismicity of the peninsula into high and low parts. von Frese et al. (2008) compared the MAGSAT scalar magnetic anomalies at an altitude of $400 \mathrm{~km}$ with seismicity of the Transcontinental Magnetic Anomaly (TMA) of the USA. They found that earthquakes predominantly concentrate in both the western and the eastern margins of TMA. Wei and $\mathrm{Yu}$ (2012) compared the surface $B_{z}$ calculated by the two CHAMP LMF models MF6 (Maus et al. 2008) and MF7 with the seismicity of Mainland China during 20042010. They found that most epicenters are located near areas with zero $B_{z}$.

These researchers (Taylor et al. 2008; von Frese et al. 2008; Wei and Yu 2012) reported correlation between seismicity and the satellite magnetic anomaly, but they did not perform a rigorous statistical inspection of this correlation. Furthermore, they attributed the seismicmagnetic correlation to the stress field. Wei and $\mathrm{Yu}$ (2012) even built a magneto-elastic model to explain such correlation. Stress variation is a key factor in triggering earthquakes, yet the piezomagnetic effect may not be large enough to generate magnetic anomaly which could be observed by satellite (Stuart et al. 1995). Other mechanisms for this correlation, however, need to be explored.

In this paper, we first reexamine the correlation between LMF and tectonics. We then use statistics to address how well LMF demonstrates seismicity. After this, we propose a two equal source dipole (TESD) model to explain the correlation between seismicity and LMF. Furthermore, we inspect how the TESD model changes with input parameters. Finally, we draw conclusions and make discussions.

\section{The LMF model and active tectonics The NGDC-720 LMF model}

Maus (2010) built the NGDC-720 LMF model by combining data from satellites (for long wavelength) and from near the surface (for short wavelength). The broad spectrum of this model suits the study of tectonics at diverse lengths. It is represented via spherical harmonic analysis (SHA) and gives the components $\left(B_{x}, B_{y}, B_{z}\right)$ directly on the surface. More details need calculation, such as magnetic anomalies at higher altitudes, and the anomaly gradients. In SHA, the magnetic potential $U^{\mathrm{LMF}}$ is presented as:

$$
\begin{aligned}
& U^{\mathrm{LMF}}(r, \theta, \phi)=a \sum_{n=16}^{720} \sum_{m=1}^{n}\left(\frac{a}{r}\right)^{n+1} \\
& \times\left(g_{n}^{m} \cos m \varphi+h_{n}^{m} \sin m \varphi\right) P_{n}^{m}(\cos \theta)
\end{aligned}
$$

in which $a$ is the Earth's reference radius ( $a=6371.2 \mathrm{~km})$, $r, \theta$, and $\phi$ are the radius, geocentric co-latitude, and longitude, respectively, $g_{n}^{m}$ and $h_{n}^{m}$ are the spherical harmonic coefficients (also called Gauss coefficients), and $P_{n}^{m}$ is the Schmidt semi-normalized associated Legendre function of integer degree $n$ and order $m$. The degree $n$ for LMF is conventionally taken from 16 , because the rest part of LMF is thought to be masked by the main or core field (Olsen et al. 2007). The horizontal spatial wavelength $\lambda$ (in $\mathrm{km}$ ) is associated with each degree by Backus et al. (1996):

$$
\lambda=\frac{2 \pi a}{\sqrt{n(n+1)}} \approx \frac{2 \pi a}{n}
$$

Thus, Formula (1) gives the magnetic potential for wavelengths between $56 \mathrm{~km}(n=720)$ and $2500 \mathrm{~km}$ $(n=16)$. The Gauss coefficients of the NGDC-720 model were calculated from the EMAG2 grid (Maus et al. 2009), which is a combination of satellite, airborne, and marine data. Aeromagnetic data from Mainland China and surroundings used in EMAG2 were provided by GETECH (http://www.getech.com/) and CCOP (http://www.ccop. or.th/). The low degree $(16 \leq n \leq 120)$ coefficients are replaced by the MF6 model (Maus et al. 2008), which was built with CHAMP low orbital $(<350 \mathrm{~km})$ data from 2004 to 2007.

The intensity and all other components, including inclination and declination, can be calculated from Formula (1). Because of inclined magnetization, reduction to the pole (RTP) is routinely used to align scalar magnetic data to the source underground (Arkani 2007). While for the vector data, especially for the vertical (downward) component $B_{z}$, RTP is not a necessary process. Sometimes, $B_{z}$ is used directly in tectonic applications (Purucker et al. 1998; Maule et al. 2005; Rajaram et al. 2009; Kang et al. 
2012; Gao et al. 2013). Because of good correspondence between satellite $B_{z}$ and tectonics, here we also use $B_{z}$ :
River fault lies on the northeastern boundary of the eastern Himalayan syntaxis $\left(\mathrm{E} 92^{\circ}-100^{\circ}, \mathrm{N} 22^{\circ}-28^{\circ}\right)$ positive

$$
B_{z}=-\sum_{n=16}^{720} \sum_{m=0}^{n}(n+1)\left(\frac{a}{r}\right)^{n+2}\left(g_{n}^{m} \cos m \phi+h_{n}^{m} \sin m \phi\right) P_{n}^{m}(\cos \theta)
$$

To study the distribution of magnetic anomalies with different horizontal wavelengths, we may select different ranges of degree $n$, as did Kang et al. (2012). Since anomalies with different wavelengths have different attenuating characters, an alternative would be to select a different $r$. In a former study (Jiao et al. 2013), we visually compared seismicity to magnetic anomalies at altitudes $(H=0 \mathrm{~km}$, $50 \mathrm{~km}, 100 \mathrm{~km}, 200 \mathrm{~km}$ and $400 \mathrm{~km}$ ). We found that $B_{z}$ at $200 \mathrm{~km}$ is mostly associated with seismicity. As a result, in this study, we focused on $B_{z}$ at $200 \mathrm{~km}$.

\section{$B_{z}$ and active tectonics}

The continental crust has stronger anisotropic structures than those of the oceanic crust. For Mainland China, the crustal tectonic heterogeneity is mainly characterized by horizontal blocks and vertical layers. Hinted by studies of active faults, folds, basins, volcanoes, earthquakes, and the GPS measurements of ground motion, the tectonics of Mainland China are divided by 6 level I and 22 level II active blocks (Deng et al. 2002; Zhang et al. 2003), as shown in Fig. 2. LMF is generated by magnetization of magnetic minerals residing in the crust and part of the upper mantle (Thébault et al. 2010). Because various minerals at different temperatures and pressures may exhibit diverse magnetization characteristics, the anisotropy of the continental crust could well be reflected in the distribution of LMF, as shown in direct comparisons (Frey 1982; Achache et al. 1987; Kang et al. 2012). To reexamine this reflection with recent LMF model, $B_{z}$ at an altitude of $200 \mathrm{~km}$ is calculated $\left(0.5^{\circ} \times 0.5^{\circ}\right.$ grids $)$ by Formula (3), and plotted in colors in Fig. 2.

Comparing LMF to tectonics (Fig. 2) reveals remarkable features. First, different types of tectonic units exhibit obviously different magnetic anomalies. Stable continents such as basins (Sichuan, Tarim, Junggar, Songliao) and cratons (North China) show obvious positive anomalies, whereas active orogens (Himalaya, Mount Tian and Mount Yin) and plateaus (Tibet) show obvious negative anomalies. Second, faults tend to lie along the boundaries of these distinct anomalies. For instance, the West Kunlun fault and the Altyn fault lie along the respective western and southern boundaries of the Tarim positive anomaly. The Mount Min-Mount Longmen fault and the Anning River-Xiaojiang fault follow the western boundary of the Sichuan basin positive anomaly, and the Red anomaly. Some Level II faults, though they have no obvious correlation with $B_{z}$ at $200 \mathrm{~km}$ altitude, do correlate well with $B_{z}$ at the surface (Kang et al. 2012).

To study the integral tectonics of the research area, the GPS movements and $B_{z}$ are drawn together in Fig. 3, and the exponent of vertically averaged effective viscosity (calculated by the hard rheological model in Deng and Tesauro 2016) is drawn in Fig. 4. As a whole, the tectonics of Mainland China is controlled by the underthrusting of stiff ( $\eta$ in green and blue) India plate (where positive magnetic anomalies of $>16 \mathrm{nT}$ dominate) from southwest and Pacific plate ( $\eta$ in green) from southeast (Zhao et al. 2011). The converging of plates generates heat via extrusion on the surface or friction near the boundary, thus uplifts the Curie isotherm, brings obvious negative anomaly, and weakens the lithospheric strength ( $\eta$ in red). Under these effects, negative anomalies $(<-8 \mathrm{nT})$ dominate Tibet plateau. The extrusion (northward movement at a rate of $36-40 \mathrm{~mm} /$ year measured on the south of Himalaya, and eastward movement at a rate of 21-26 mm/year measured on the east boundary of the Tibet plateau, see Wang et al. (2001) and Zhang et al. (2004b) of Tibetan crust (weak, $\eta$ in red) is resisted by the old and cold (strong) basins of Tarim ( $\eta$ in yellow and green, with GPS velocity decreasing to $4.7 \mathrm{~mm} /$ year NE in Tianshan) and Sichuan ( $\eta$ in yellow and green, with GPS velocity decreasing to 6-10 $\mathrm{mm}$ /year SE in South China), where obvious positive anomalies (>24 nT) dominate. The northward extrusion of Tibet is also resisted by Qaidam basin (relative strong, $\eta$ in orange), where the anomaly is only slightly positive $(\sim 4 \mathrm{nT})$. Extrusion thus finds its paths in the northeast and southeast direction, leading to an obvious negative anomaly $(<-12 \mathrm{nT})$ in the northeast of Bayan Har block (14-17 mm/year NE) and a slightly negative anomaly $(\sim-4 \mathrm{nT})$ in Chuandian block ( $20 \mathrm{~mm}$ /year SES). The northeast part develops continually northward, resulting in negative anomaly patches $(-8 \mathrm{nT})$ in Qilian $(\sim 7 \mathrm{~mm} /$ year NE) and even the west of Ordos block ( $\sim 6 \mathrm{~mm} /$ year SE). Subjected to the combined effects of India and Pacific underthrusting, the ancient North China craton $(\sim 7 \mathrm{~mm} /$ year SE) is destroyed and only shows moderate positive anomaly $(<12 \mathrm{nT})$. The anomaly in North China craton is very different from the other two Precambrian cratons of Tarim (Tarim block) and Yangtze (in the northwest of South 


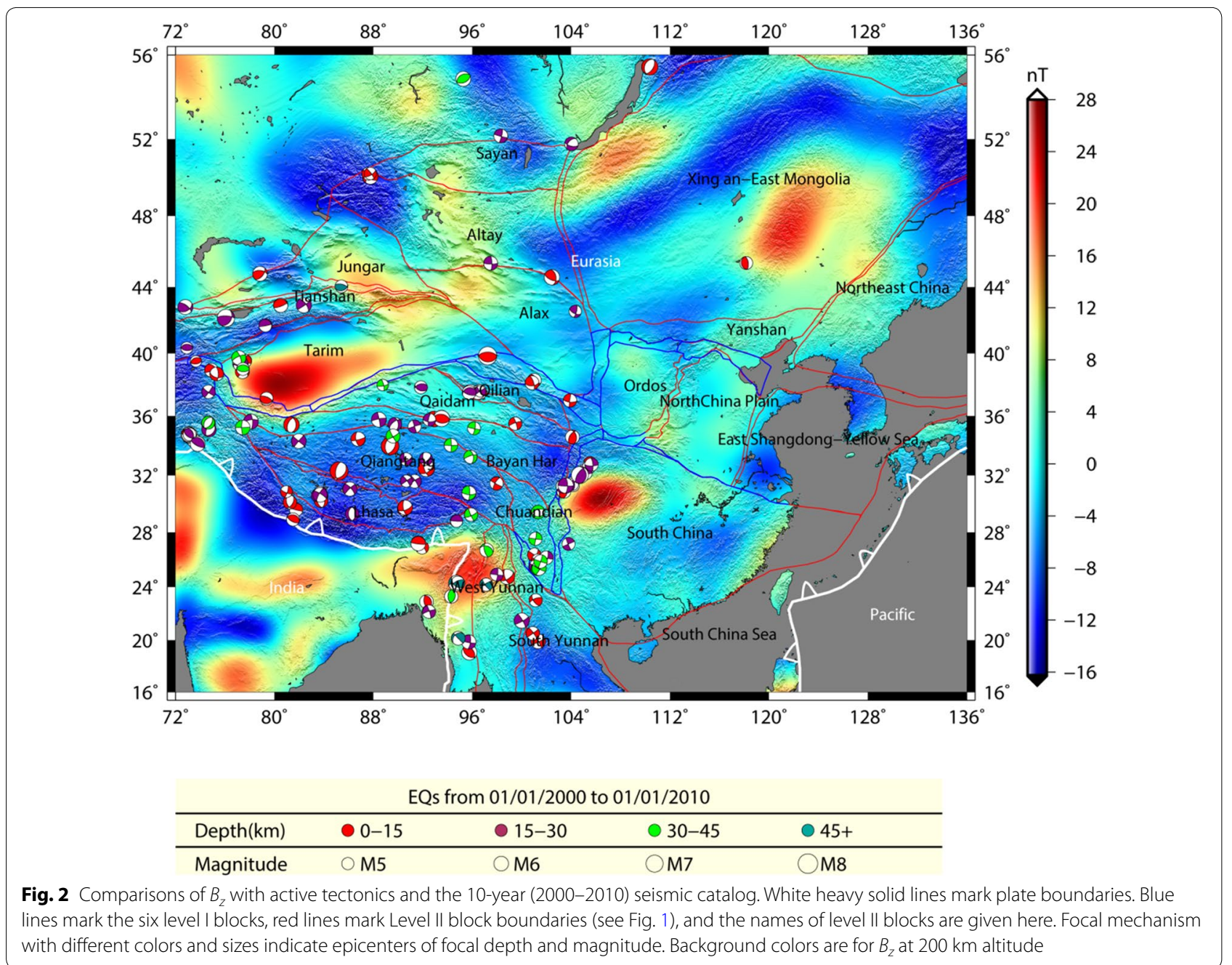

China Block), which may be a magnetic manifestation of craton destruction or lithospheric thinning (Zhu et al. 2012). The irregularity of magnetic distribution in North China also indicates the spatial complexity of craton destruction.

In general, active blocks, faults, GPS movements and lithospheric strength in Mainland China all have close correlations with $B_{z}$. Boundaries of obvious magnetic anomalies often signify boundaries of active blocks or large faults (Fig. 3). Large GPS movements usually appear inside areas with obvious negative $B_{z}$ (e.g. Tibet, Tianshan and Chuandian). Moreover, the GPS movements tend to decrease dramatically through negative $B_{z}$ areas, which is most obvious in Tibet. Areas with obvious negative $B_{z}$ often effect as absorbing the displacement, which result in crustal shortening and uplifting. By contrast, areas with obvious positive $B_{z}$ (e.g. Tarim and Sichuan Basin) often effect as resisting, slowing and transmitting the crustal displacement, without obvious internal deformation. As for $B_{z}$ and the lithospheric strength, strong lithosphere is commonly corresponding to obvious positive $B_{z}$ (e.g. Tarim, Sichuan, Songliao and North China), and weak lithosphere is usually related to obvious negative $B_{z}$ (e.g. Tibet and Chuandian, Fig. 4).

\section{Correlation between seismicity and magnetic anomaly} Seismicity and $B_{z}$

The correlation between seismicity and the structure of fault zones or crustal deformation in Mainland China has been investigated (e.g. James et al. 1976; Wesnousky et al. 1984; Zhang et al. 2004a). In this study, we focus on the correlation between seismicity and magnetic anomaly.

The correlation between magnetic anomalies and tectonics lays the foundation for the correlation between magnetic anomalies and seismic activities. We use the International Seismological Centre (ISC) reviewed 


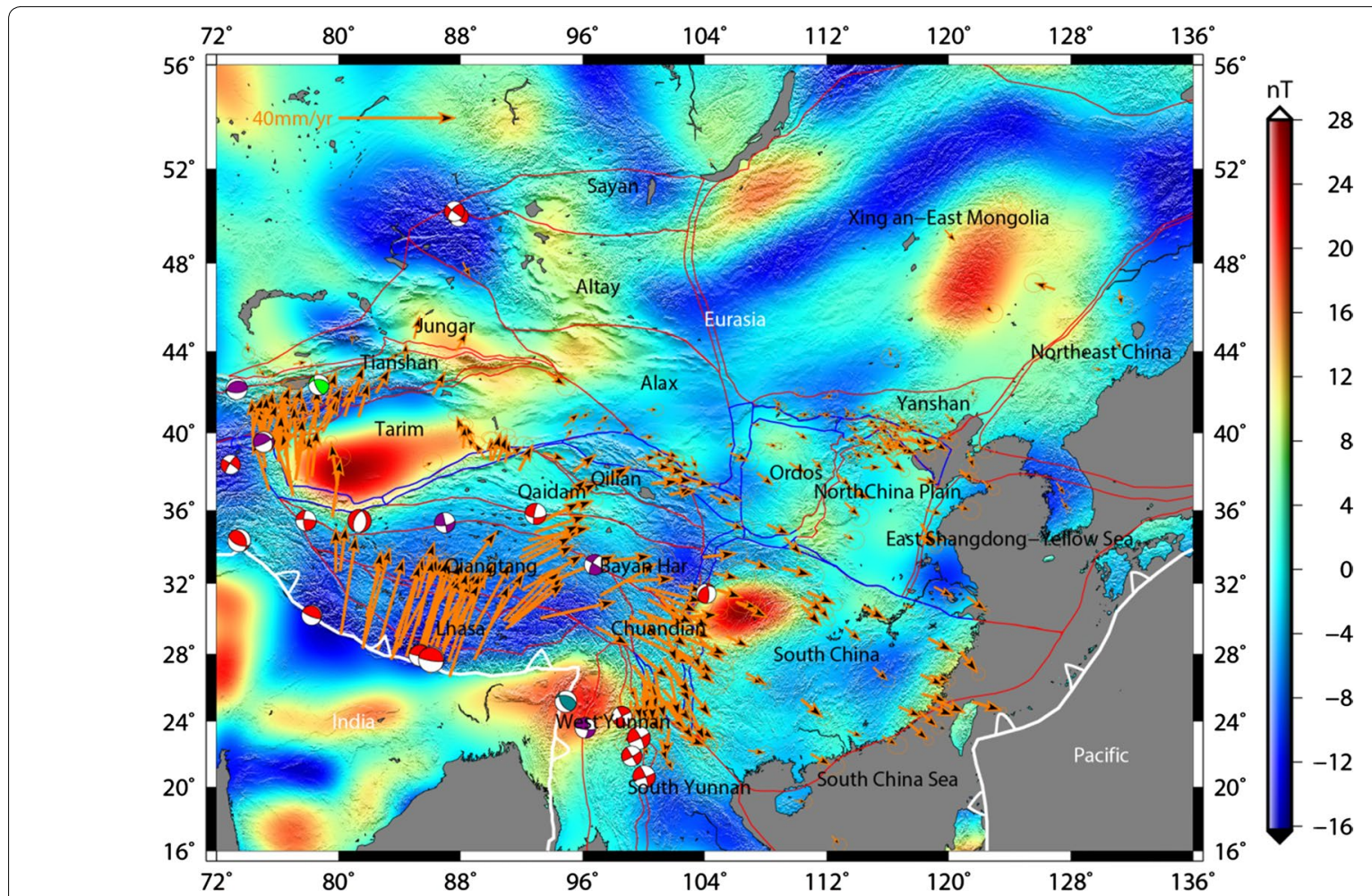

Fig. 3 Comparisons of $B_{z}$ at $200 \mathrm{~km}$ altitude with active tectonics and the megaseisms ( $\left.>M_{s} 7.0\right)$ catalog between 1976 and 2018. Background colors are for $B_{z}$ at $200 \mathrm{~km}$ altitude. Orange arrows mark the GPS velocity vectors ( $\mathrm{mm} /$ year). Lines with different colors mark boundaries of different tectonic units (see Figs. 1, 2)

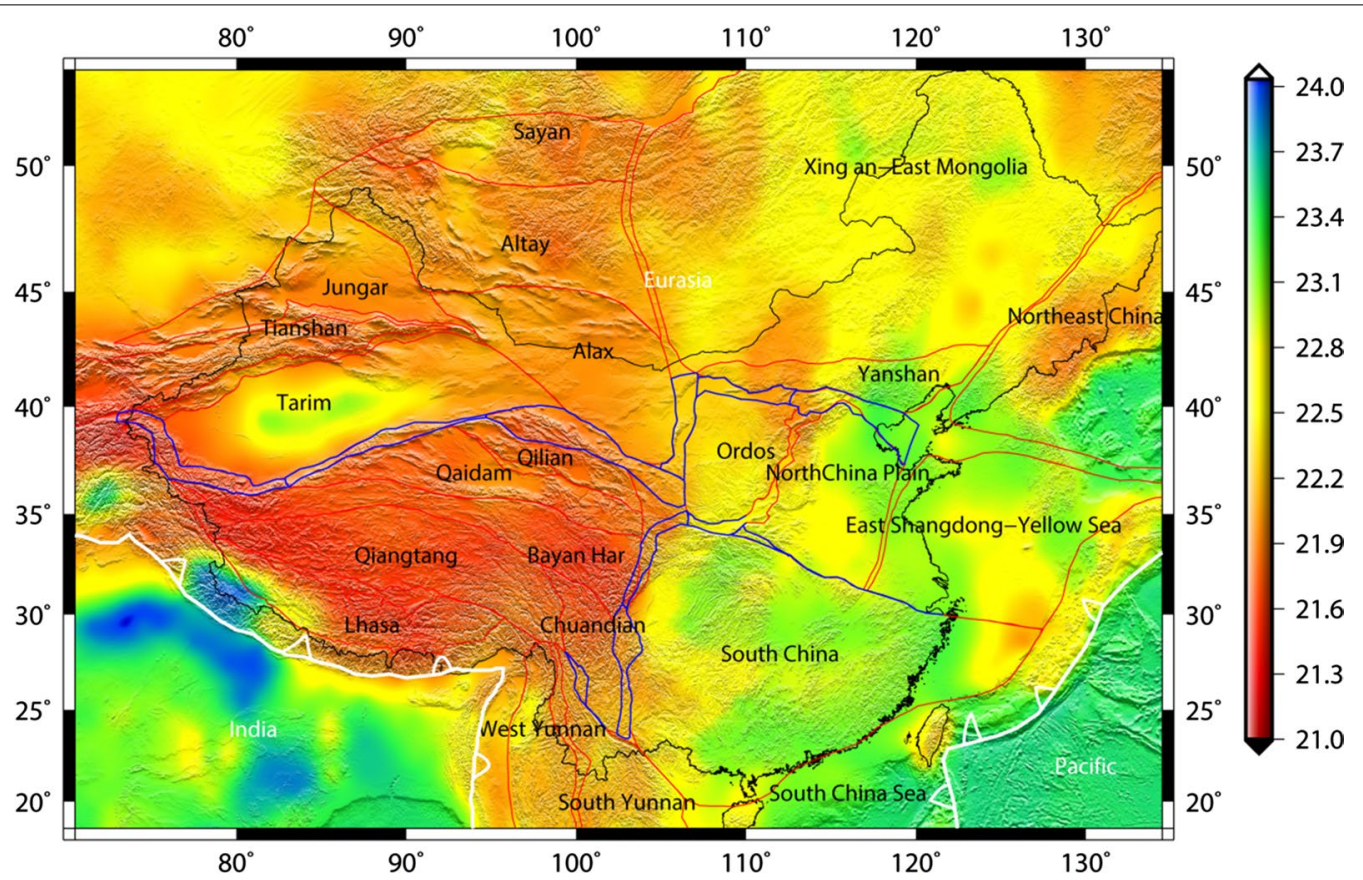

Fig. 4 Exponent of vertically averaged effective viscosity $(\eta)$ variations of the lithosphere (viscosity data are provided by YF Deng, see Deng and Tesauro 2016). Lines with different colors mark boundaries of different tectonic units (see Figs. 1, 2) 
seismic catalogue to compare seismicity with LMF. Our research area is $\left(E 72^{\circ}-136^{\circ}, \mathrm{N} 16^{\circ}-56^{\circ}\right)$, where 595 earthquakes with magnitudes larger than $M_{s} 5.0$ occurred in the continental area. The satellite magnetic data used by the NGDC-720 model range from 2004 to 2007 . To compare seismicity in different periods and to check the validated period of the LMF model, we studied records of three periods: 2004-2007 (77 records), 2000-2010 (222 records) and 1978-2011 (595 records). Taking the 20002010 period as an example, in Fig. 2 we show the comparison between seismicity (marked by colored spheres) and $B_{z}$.

The spatial distribution of seismicity in Mainland China exhibits tremendous inhomogeneity. Most earthquakes occurred in west China, especially inside and near the boundary of Tibet plateau, and only one $\left(M_{s}>5.0\right)$ occurred in east China in this period. For the focal depth, shallow $(<30 \mathrm{~km})$ earthquakes mostly occurred inside Tibet plateau and deep earthquakes $(>30 \mathrm{~km})$ usually occurred near the north and east boundary of Tibet plateau. For the focal mechanisms, thrust earthquakes are mainly distributed on the Himalaya collision boundary, while extensional and strike-slip earthquakes are distributed inside Tibet plateau, and thrust and strike-slip earthquakes occurred along the north and east boundary of Tibet plateau. As for the correlation between $B_{z}$ and earthquakes, Fig. 2 illustrates four phenomena: (1) More earthquakes have occurred in areas with negative anomalies than in areas with positive anomalies; (2) few earthquakes occurred inside predominant anomalies, either positive (e.g. basin anomalies) or negative (the two obvious anomalies located near the plate boundary of India and Eurasia); (3) numerous earthquakes occurred near zero $B_{z}$ areas (around the Sichuan Basin anomaly), or near boundaries of obvious anomalies (such as the Tarim Basin anomaly); (4) for distributions of earthquakes that deviate from the above three rules, rules 1-3 could be reproduced by selecting earthquakes with magnitude larger than $M_{s} 7.0$, or by selecting earthquakes with a focal depth deeper than $30 \mathrm{~km}$, such as those near the boundary of the whole Tibetan negative anomaly (Jiao et al. 2013).

For a more directly illustration of above characters, only earthquakes with magnitude larger than $M_{s} 7.0$ occurred in 1976-2018 were selected and drawn in Fig. 3. As can be seen, megaseisms are distributed mainly along boundaries of obvious magnetic anomalies. Earthquakes with all the three types of focal mechanisms could occur on the boundaries of positive or negative magnetic anomalies. No direct correlation between focal mechanism and magnetic anomaly is shown here.

To study the distribution signature of seismicity quantitatively and to compare earthquakes occurred in different periods, we performed a statistical analysis. The results are shown in Fig. 5. To specify the magnetic anomalies in the vicinity of the epicenters we noted the longitude and latitude of the epicenter, picked out the four nearby magnetic anomaly nodes, and calculated the average of these nodes. We uniformly divided the whole range of magnetic anomalies by an interval of $2 \mathrm{nT}$ (depending on the amplitude of the anomaly), and we counted the number of earthquakes occurring in each interval. The statistical results for the three periods are shown in Fig. $5 \mathrm{a}-\mathrm{c}$, respectively.

Both of histograms and boxplots are shown in Fig. 5 . First, let us check the histograms. Oblique numbers atop the corresponding histograms represent ratios of the maximum records within the magnetic interval to the total records, and oblique numbers inside the small box beside the histograms represent ratios of records within the negative anomalies to the total records. As is shown, most earthquakes concentrate in areas with small magnetic anomalies, while few earthquakes are located in areas with dominant anomalies. The records peak at $B_{z}=-5 \sim-3 \mathrm{nT}$ for all three periods. Increasing the time interval decreases the peak ratio from $53.2 \%$ (2004-2007) to $20.5 \%$ (1978-2011). Meanwhile, the ratio of records that occur inside negative anomalies also decreases from $81.8 \%$ (2004-2007) to $65.2 \%(1978-2011)$.

It is too early to conclude whether earthquakes tend to occur more frequently in areas with negative anomalies, or especially with $B_{z}=-5 \sim-3 \mathrm{nT}$. What if the negative anomaly itself is dominant in the research area? Thus, the background distribution of $B_{z}$ (Fig. 5d) needs to be checked. In other words, Fig. $5 \mathrm{~d}$ shows the average statistical distribution of seismicity when there is no correlation between magnetic anomalies and seismicity. As can be seen, for the total 8932 grid nodes, the distribution peaks also at $B_{z}=-5 \sim-3 \mathrm{nT}$, and the ratios are $52.7 \%$ (negative anomaly) and $11.3 \%\left(B_{z}=-5 \sim-3 \mathrm{nT}\right)$, respectively.

Next, let us check the boxplots, which are on top of histograms in Fig. 5. Boxplot (Robert et al. 1978) is a method for graphically depicting groups of numerical data through their quartiles. In the boxplot, the median (red line), first quantile (blue vertical line on the left, Q1) and third quantile (blue vertical line on the right, Q3) of the data are first calculated. Then, the two limits are calculated customarily by extending 1.5 times of the box width (equals to Q3-Q1) to both sides. Data outside the two limits are outliers. Outliers are sometimes used to eliminate extreme or disturbed data. The coefficient 1.5 could be replaced by 3 in other cases, noting that the selection of the coefficient does not affect lines inside the box.

As is shown in Fig. 5, all the four boxplots exhibit concentrated distributions (a half samples are inside 

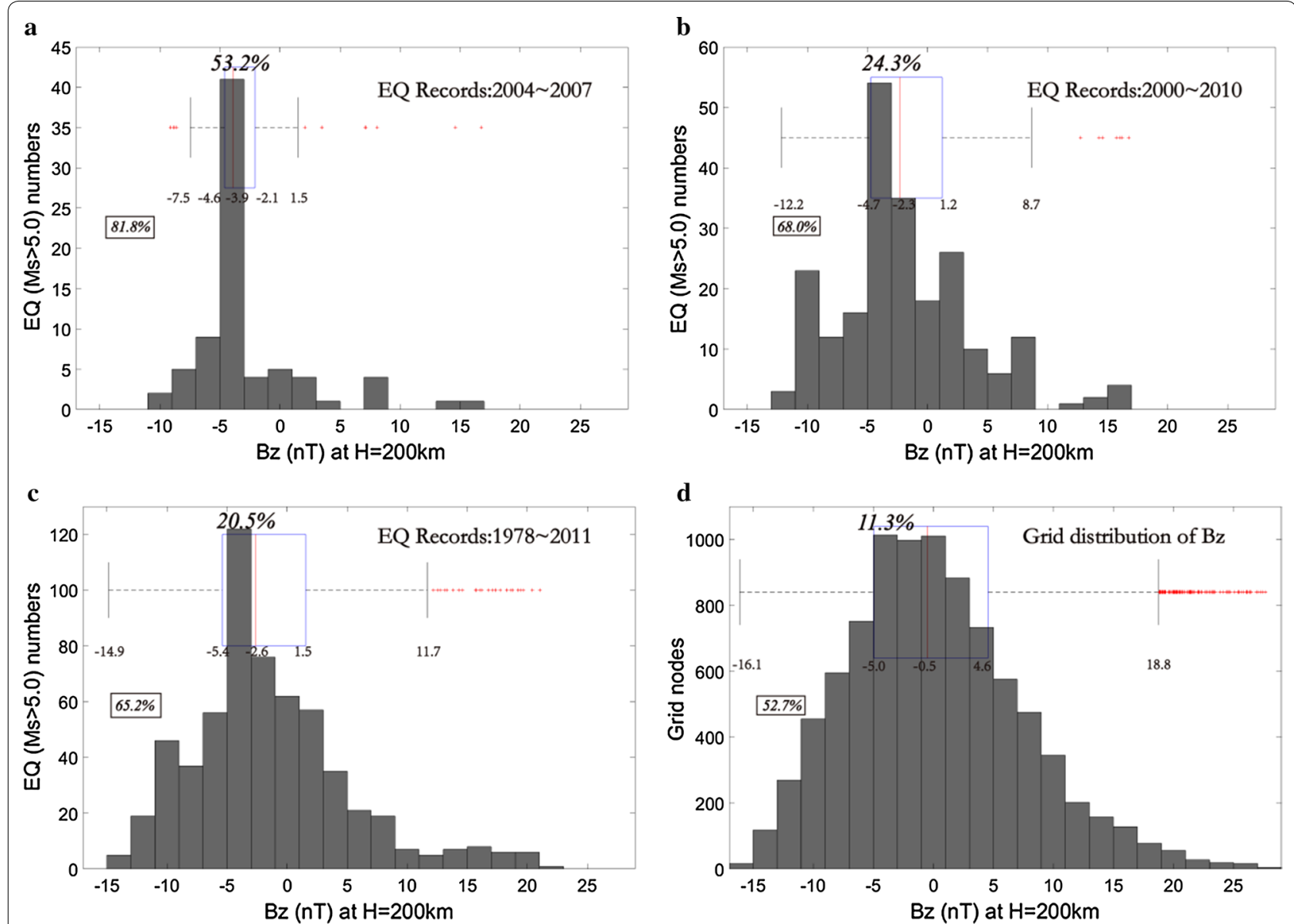

Fig. 5 Histograms and boxplots for the distribution of seismicity over $B_{z}$. a-c Different time intervals, respectively. $\mathbf{d}$ The statistical distribution of $B_{z}$ grid nodes. See details in the text

the narrow box nearby the median lines), and gradually increase in concentration appears when checking from Fig. $5 \mathrm{~d}$ to a (both of the whole range and the half sample box become narrower). Especially, a quarter large earthquakes occurred inside a very narrow $B_{z}$ box of $0.7 \mathrm{nT}$ width $(-4.6$ to $-3.9 \mathrm{nT})$ for the time period of 20042007. The medians shift left gradually from $-0.5 \mathrm{nT}$ (grid distribution) to -3.9 nT (2004-2007). Furthermore, there is good consistency between the left part of each box (limited by Q1 and the meridian) and the dominate histogram when comparing the boxplots and histogram plots for each time period.

All the four histogram plots in Fig. 5 failed to pass the rigorous normal distribution test; we thus seek for nonparametric statistical tools, e.g. the KolmogorovSmirnov test (Kolmogorov 1933; Smirnov 1948). The two-sample $\mathrm{K}-\mathrm{S}$ test is one of the most useful and general nonparametric methods for comparing two samples, as it is sensitive to differences in both location and shape of the empirical cumulative distribution functions of the two samples. The null hypothesis for $\mathrm{K}-\mathrm{S}$ test is that the two groups have the same overall distributions, against the alternative hypothesis that they have not. Using $\mathrm{K}-\mathrm{S}$ test, we calculate the $h$ values and $p$ values between the background grid distribution and the seismic distributions for different time periods, which is shown in Table 1.

The test result has two parameters: $h$ and $p . h$ is the hypothesis test result, returned as 1 or 0 . If $h=1$, it indicates the rejection of the null hypothesis at a certain significance level (defaulted as 5\%). If $h=0$, it indicates

Table $1 h$ and $p$ value of K-S test

\begin{tabular}{llll}
\hline $\begin{array}{l}\text { Statistic value/ } \\
\text { time period }\end{array}$ & 2004-2007 & 2000-2010 & $\mathbf{1 9 7 8 - 2 0 1 1}$ \\
\hline$h$ & 1 & 1 & 1 \\
$p$ & $2.19 \times 10^{-10}$ & $5.48 \times 10^{-7}$ & $1.58 \times 10^{-10}$ \\
\hline
\end{tabular}


a failure to reject the null hypothesis at a certain significance level. The other parameter $p$ is the probability, which denotes the degree of supporting the null hypothesis. If $p<0.05$, it indicates that the null hypothesis is rejected at a significance of $5 \%$.

As is shown in Table $1, h=1$ and $p \ll 0.05$ hold for all the three time periods, which shows that in all the three time periods, the seismicity distributions are very different from the background grid distribution. Other statistical tools, e.g. Mann-Whitney $U$ (Mann and Whitney 1947) and Kruskal-Wallis (Kruskal and Wallis 1952) test, have been also applied, and we got similar results. These indicate that the spatial distribution of earthquakes is influenced remarkably by $B_{z}$.

To study quantitatively the influence of $B_{z}$ on the spatial distribution of continental seismicity, we propose an earthquake-magnetic ratio $q_{\mathrm{EM}}$ to measure the magnetic seismic susceptibility as:

$$
q_{\mathrm{EM}}=p_{\mathrm{M}} / p_{\mathrm{B}}
$$

in which $p_{\mathrm{M}}$ is the statistical percentage of seismic records in a certain magnetic interval and $p_{\mathrm{B}}$ is the corresponding statistical percentage of the background grid nodes in the same magnetic interval. Where $q_{\mathrm{EM}}>1$, earthquakes tend to occur in the given magnetic interval, so the risk of seismicity is higher. Where $q_{\mathrm{EM}}<1$, the risk of seismicity is lower. During 2004-2007 (Fig. 5a), for example, the $q_{\mathrm{EM}}$ for earthquakes that occur within a negative anomaly is $q_{\mathrm{EM}}=81.8 \% / 52.7 \%=1.6$, while for $B_{z}=-5 \sim-3 \mathrm{nT}$, the $q_{\mathrm{EM}}=53.2 \% / 11.3 \%=4.7$. These calculations demonstrate the higher likelihood of seismicity for areas with negative $B_{z}$ or $B_{z}=-5 \sim-3 \mathrm{nT}$.

The $q_{\mathrm{EM}}$ distribution for each time period is plotted in Fig. 6 . As can be seen, $q_{\mathrm{EM}}$ is always largest in the magnetic range of -5 to $-3 \mathrm{nT}$ for the three time periods, and it is most remarkable in 2004-2007. When the time intervals are extended, $q_{\mathrm{EM}}$ decreases from 1.6 and 4.7 (2004-2007) to 1.2 and 1.8 (1978-2011), for negative $B_{z}$ and $B_{z}=-5 \sim-3 \mathrm{nT}$, respectively. Usually, larger $q_{\mathrm{EM}}$ areas deserve more attention, while the large $q_{\mathrm{EM}}$ areas in the both ends of $B_{z}$ (Fig. 6b, c) should be noted as exceptions, because that few earthquakes occurred inside these areas.

\section{Seismicity and the gradient of $B_{z}$}

When comparing $B_{z}$ to seismicity in Fig. 2, we realized numerous earthquakes were located near zero $B_{z}$ belts (similar to Wei and Yu 2012), or near boundaries of strong anomalies (similar to von Frese et al. 2008). We have just studied the zero $B_{z}$ belts, and now continue to study the boundaries, which resemble the gradient belts of anomalies. Former studies (e.g. Zhang et al. 2010) indicated that most earthquakes occurred along the
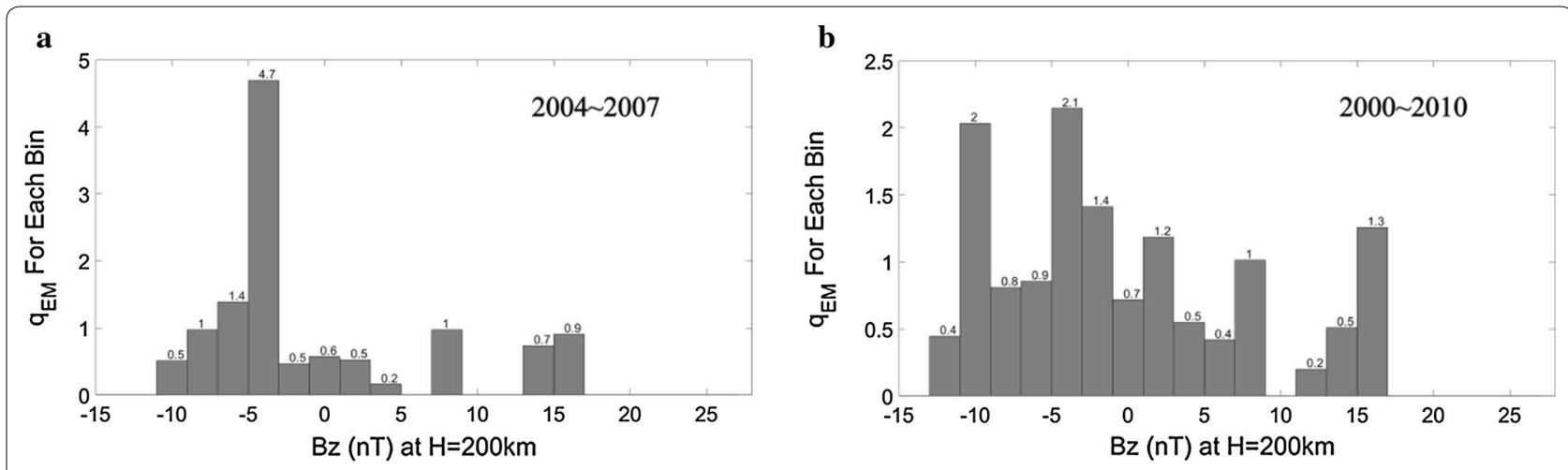

c
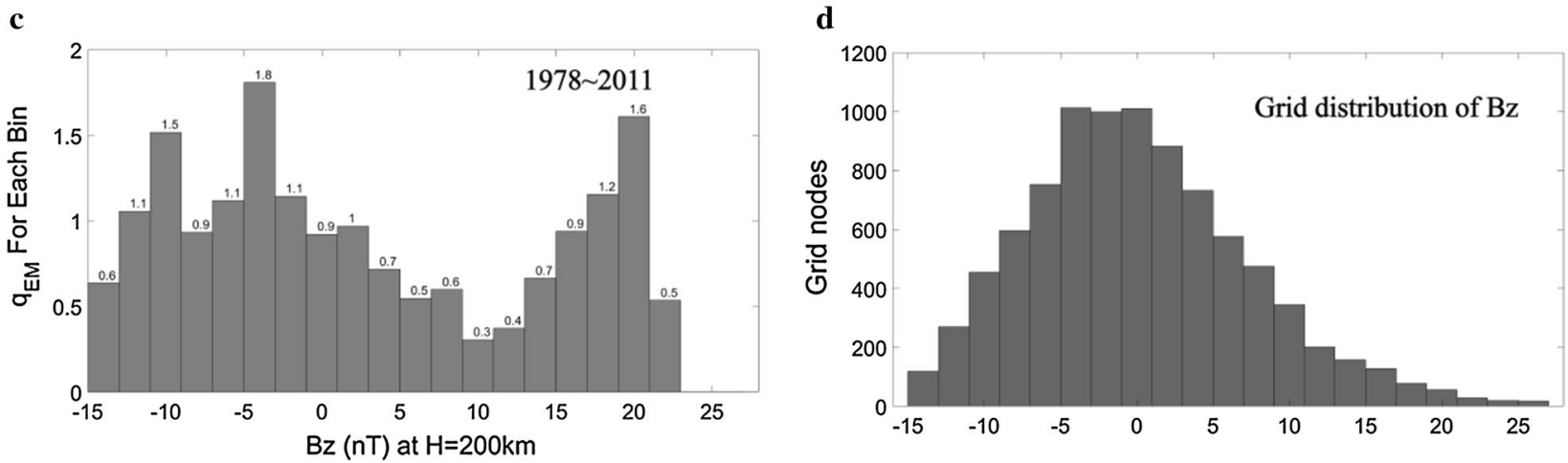

Fig. $6 q_{\mathrm{EM}}$ for each time period. a-c Different time intervals, respectively. $\mathbf{d}$ The statistical grid distribution of $B_{z}$ 
horizontal gradient belts of the residual gravity anomaly. Since both magnetic field and gravity field are geopotential fields, we could also compare seismicity and magnetic anomaly gradient.

The gradient of $B_{z}$ can be obtained by calculating the derivative of Formula (3) in spherical coordinates, and the horizontal gradient

$$
\left|\nabla_{\mathrm{H}} B_{z}\right|=\sqrt{\left(\partial_{x} B_{z}\right)^{2}+\left(\partial_{y} B_{z}\right)^{2}}=\sqrt{\left(-\partial_{\theta} B_{z}\right)^{2}+\left(\partial_{\varphi} B_{z}\right)^{2}}
$$

We compared $\left|\nabla_{\mathrm{H}} B_{z}\right|$ with tectonics and seismicity in Fig. 7. As can been seen, some faults are along gradient

$$
\begin{aligned}
\nabla B_{z}= & \hat{e}_{r} \partial_{r} B_{z}+\hat{e}_{\theta} \frac{\partial_{\theta} B_{z}}{r}+\hat{e}_{\phi} \frac{\partial_{\phi} B_{z}}{r \sin \theta} \\
= & \hat{e}_{r} \sum_{n=16}^{720} \sum_{m=0}^{n}(n+1)\left(\frac{a}{r}\right)^{n+2} \frac{n+2}{r}\left(g_{n}^{m} \cos m \phi+h_{n}^{m} \sin m \phi\right) P_{n}^{m}(\cos \theta) \\
& +\hat{e}_{\theta} \sum_{n=16}^{720} \sum_{m=0}^{n}-(n+1)\left(\frac{a}{r}\right)^{n+2}\left(g_{n}^{m} \cos m \phi+h_{n}^{m} \sin m \phi\right) \frac{\partial P_{n}^{m}(\cos \theta)}{r \partial \theta} \\
& +\hat{e}_{\phi} \frac{1}{r \sin \theta} \sum_{n=16}^{720} \sum_{m=0}^{n}(n+1)\left(\frac{a}{r}\right)^{n+2}\left(g_{n}^{m} \sin m \phi-h_{n}^{m} \cos m \phi\right) m P_{n}^{m}(\cos \theta)
\end{aligned}
$$

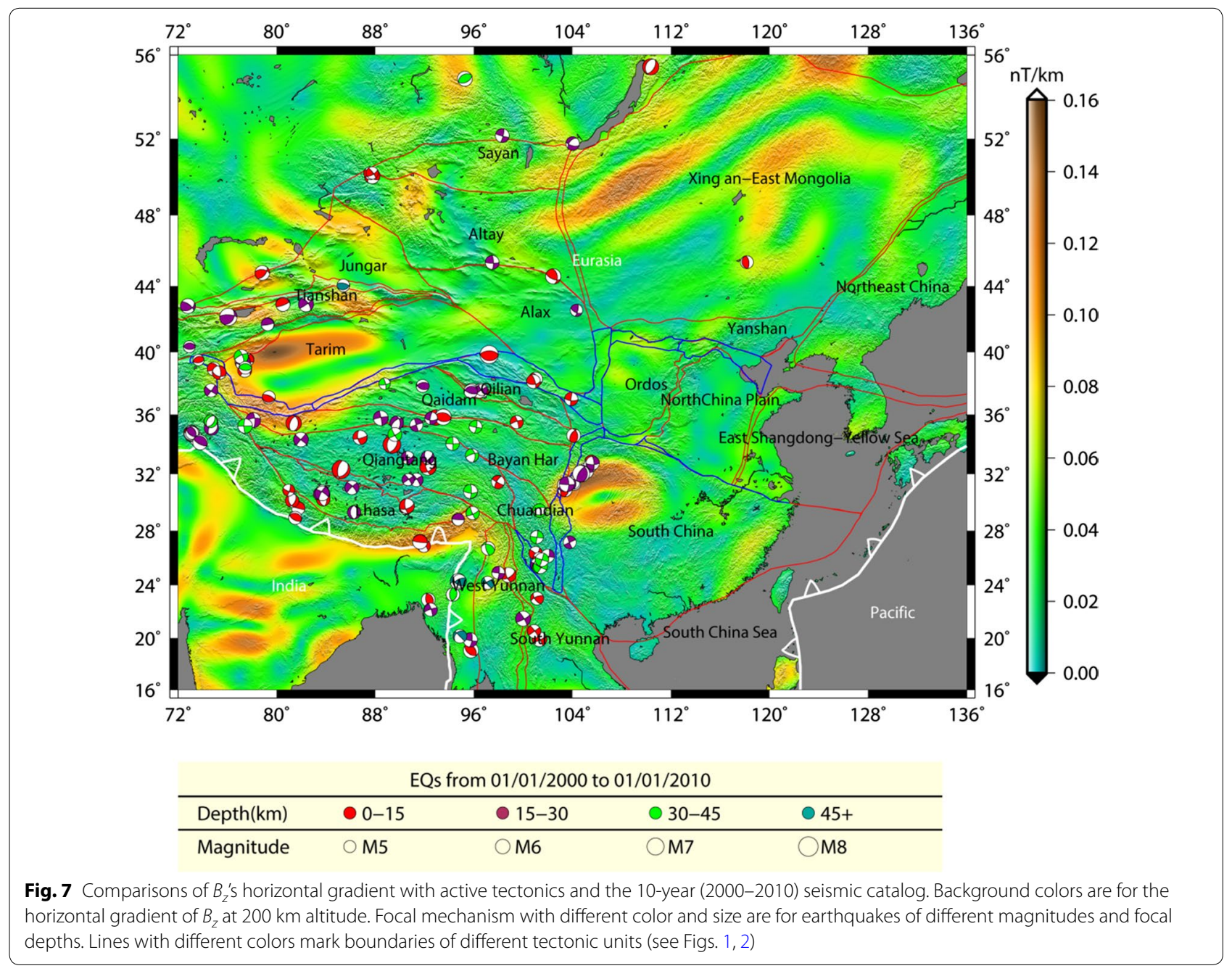


belts, such as the West Kunlun fault, the Altyn fault, the Mount Yin fault and the Tanlu fault (a deep fracture first detected by a large NNE linear positive aeromagnetic anomaly in 1957). Some earthquakes were indeed located inside magnetic gradient belts, e.g. those near the northwest of Sichuan Basin, or in the west of Tarim Basin. In contrast to previous understandings, however, more earthquakes were located near boundaries of gradient belts, such as those to the north of the $\mathrm{N} 40^{\circ}$ line, or in areas without a large magnetic gradient, such as those inside the Tibetan block. Other gradient components, such as the vertical gradient of $B_{z}$, show a similar character (see Additional file 1: Figure S1).

To obtain quantitative results, we also analyzed statistics from different time intervals. The results are shown in Fig. 8, and the gradient interval is $0.01 \mathrm{nT} / \mathrm{km}$. As Fig. 8 shows, earthquakes are mostly located in areas with a relatively weak magnetic gradient. For the three different time periods, the intervals for the maximum number of seismic records are identical at $\left|\nabla_{\mathrm{H}} B_{z}\right|=0.015-0.025 \mathrm{nT} /$ $\mathrm{km}$. The ratio of earthquakes occurring in this interval also decreases from 53.3 to $22.4 \%$ when the time interval is extended from 2004-2007 to 1978-2011. The background distribution of seismicity over $\left|\nabla_{\mathrm{H}} B_{z}\right|$ is shown in Fig. 8d. Here areas with $\left|\nabla_{\mathrm{H}} B_{z}\right|=0.015-0.025 \mathrm{nT} / \mathrm{km}$ also dominate the whole research area. The earthquakemagnetic ratio $q_{\mathrm{EM}}$ is $2.7,1.6$ and 1.1 for the time interval 2004-2007, 2000-2010, and 1978-2011, respectively.

For the total gradient $\left|\nabla B_{z}\right|$, we present the results directly. The peak value for the maximum number of earthquakes is located at $\left|\nabla B_{z}\right|=0.025-0.035 \mathrm{nT} / \mathrm{km}$, and the $q_{\mathrm{EM}}$ is 4.0, 2.6 and 1.7 for the time intervals of 2004-2007, 2000-2010, and 1978-2011, respectively. This magnetic gradient interval shifts to larger values than the horizontal gradient intervals because the vertical gradient is included. Also, in each period the $q_{\mathrm{EM}}$ for the total gradient is larger than that for the horizontal gradient, which indicates that the former is more suitable for defining seismically dangerous areas. As an indicator, $B_{z}\left(q_{\mathrm{EM}}\right.$ is 4.7 for 2004-2007) is even better than $\left|\nabla B_{z}\right|$.
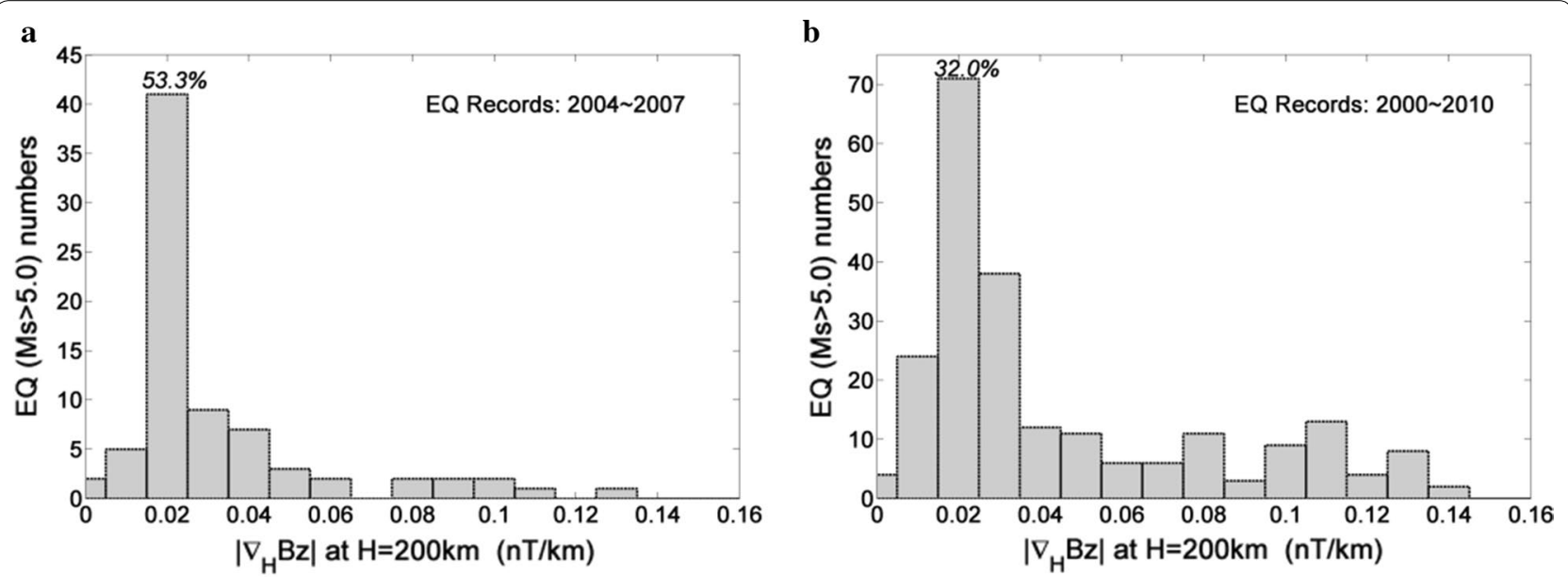

c

d
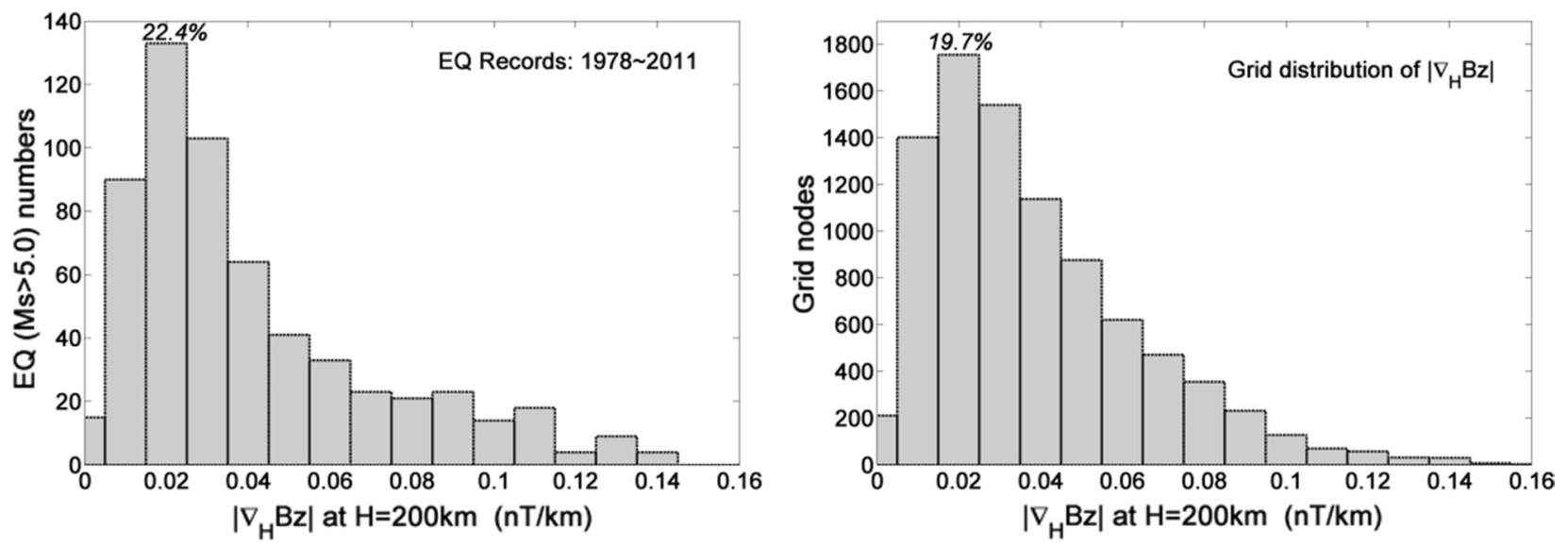

Fig. 8 The distribution of seismicity over the horizontal gradient of $B_{z}$ (refer to Fig. 5 for legends) 
Table $2 \boldsymbol{q}_{\mathrm{EM}}$ at different altitudes

\begin{tabular}{|c|c|c|c|c|c|}
\hline Altitudes (km) & 0 & 50 & 100 & 200 & 400 \\
\hline$B_{z}$ range for most earthquakes (nT) & 5 to 15 & -10 to 0 & -5 to 5 & -5 to -3 & -1.5 to -0.5 \\
\hline$q_{\mathrm{EM}}$ for $B_{z}$ & 3.6 & 2.7 & 2.1 & 4.7 & 3.3 \\
\hline $\begin{array}{l}B_{z} \text { horizontal gradient range for most earth- } \\
\text { quakes }(\mathrm{nT} / \mathrm{km})\end{array}$ & $0.55-0.65$ & $0.225-0.275$ & $0.09-0.11$ & $0.015-0.025$ & $0.007-0.009$ \\
\hline$q_{\mathrm{EM}}$ for $B_{z}$ horizontal gradient & 4.1 & 3.8 & 4.2 & 2.7 & 3.2 \\
\hline
\end{tabular}

\section{Seismicity for different altitudes and sub-regions}

Table 2 shows similar statistical analyses of $B_{z}$ for the same period 2004-2007 at different altitudes. The anomaly range for most earthquakes might not always be the same with the background grid distribution, such as the surface $B_{z}$. In this case, we selected the range for most earthquakes (5-15 nT). As Table 2 indicates, $q_{\mathrm{EM}}$ for $B_{z}$ at an altitude of $200 \mathrm{~km}$ has the largest value, thus most suitable to constrain seismicity. Furthermore, not only the earthquake number dominates in the anomaly range of -5 to $-3 \mathrm{nT}$, but also the earthquake energy. The seismic energy in this range is about two orders larger than those in any other ranges, and it composed $94.6 \%$ of all the seismic energy in this period (see the graphical abstract). $B_{z}$ at this altitude reflects well not only the seismicity, but also the topography (see Additional file 1: Figure S2). The statistical result is similar to our previous visual inspection (Jiao et al. 2013), while more accurate.

To check the earthquake distributions in different regions, we divided the whole research area into 6 subregions: Northeast China, North China, Xinjiang, Tibet, Sichuan-Yunnan and South China. Results (Additional file 1: Figure S3) show that the anomaly range of -5 to $-3 \mathrm{nT}$ for most earthquakes is valid for Northeast China and Tibet, while invalid for the other four sub-regions. Furthermore, longer time interval (110 years) with more earthquakes (1147) is also inspected, which (Additional file 1: Figure S4) shows a consistent result with Fig. 5.

\section{A theoretical model-TESD}

Our statistical analyses of seismicity showed earthquakes are more likely to occur in areas with certain magnetic anomalies. In order to explain the physical mechanism behind this phenomenon, Wei and Yu (2012) proposed a model of magnetic induction from line concentrated force in a magnetized half-plane. They based their explanations on the assumption that all the satellite magnetic anomalies are caused by concentrated stresses. This assumption, however, is far from the fact (Thébault et al. 2010). Furthermore, the small piezomagnetic effects (Stuart et al. 1995) make all the stress-related explanations futile. In our attempt to unfold the generating mechanism of the LFM, we put forward a new explanation.

\section{Curie isotherm and the LMF}

The LMF is generated by the magnetization of minerals in an ambient magnetic field, which is usually the main field. The two different magnetization mechanisms are: induced and remnant. The magnetic anomaly of the continental crust (especially tectonically stable basins and cratons) is primarily generated by induction in the current main field, while the anomaly of oceanic crust (especially the middle ocean ridges) is primarily generated by remnants in ancient main fields (Thébault et al. 2010). Since this research concerns continental seismicity, it examines magnetic anomalies generated by induction.

Studies about the distribution characteristics of satellite magnetic anomalies (e.g. Kang et al. 2010) argued that the magnitude of these anomalies correlated positively with the depth of the Curie isotherm. The Curie isotherm is a thermal boundary where ferromagnetism is converted into paramagnetism (Langel and Hinze 1998; Rajaram et al. 2009). During this process, magnetic susceptibility decreases dramatically. Therefore, the Curie isotherm is considered the lower magnetic boundary of the crust. The burial depth of the Curie isotherm is closely related to the surface heat flux (Maule et al. 2005), in that low heat flux areas are expected to have a relatively deep Curie isotherm, and vice versa. So to judge whether the Curie depth is critical for the LMF, we compared $B_{z}$ with the surface heat flux in Fig. 9.

As Fig. 9 reveals, the giant basins (Tarim, Junggar, Sichuan and Songliao) show a relatively low heat flux. Most are lower than $60 \mathrm{~mW} / \mathrm{m}^{2}$ (blue filled triangles) with a few stand-out values not higher than $80 \mathrm{~mW} / \mathrm{m}^{2}$ (green). These basins are all identified as strong positive anomalies. The heat flux in North China is usually lower than $80 \mathrm{~mW} / \mathrm{m}^{2}$, where the magnetic anomaly is slightly positive. In contrast, high heat flux is observed in Tibet and at the southeastern coast. There, the heat flux is largely higher than $60 \mathrm{~mW} / \mathrm{m}^{2}$ (green), and sometimes even higher than $140 \mathrm{~mW} / \mathrm{m}^{2}$ (white). Most of these areas are identified as negative anomalies. These indicate that in most of the research area, the Curie depth is of key importance for LMF distribution.

Though intuitively magnetic low corresponds to high heat flow, some areas (such as South China) seem to be 


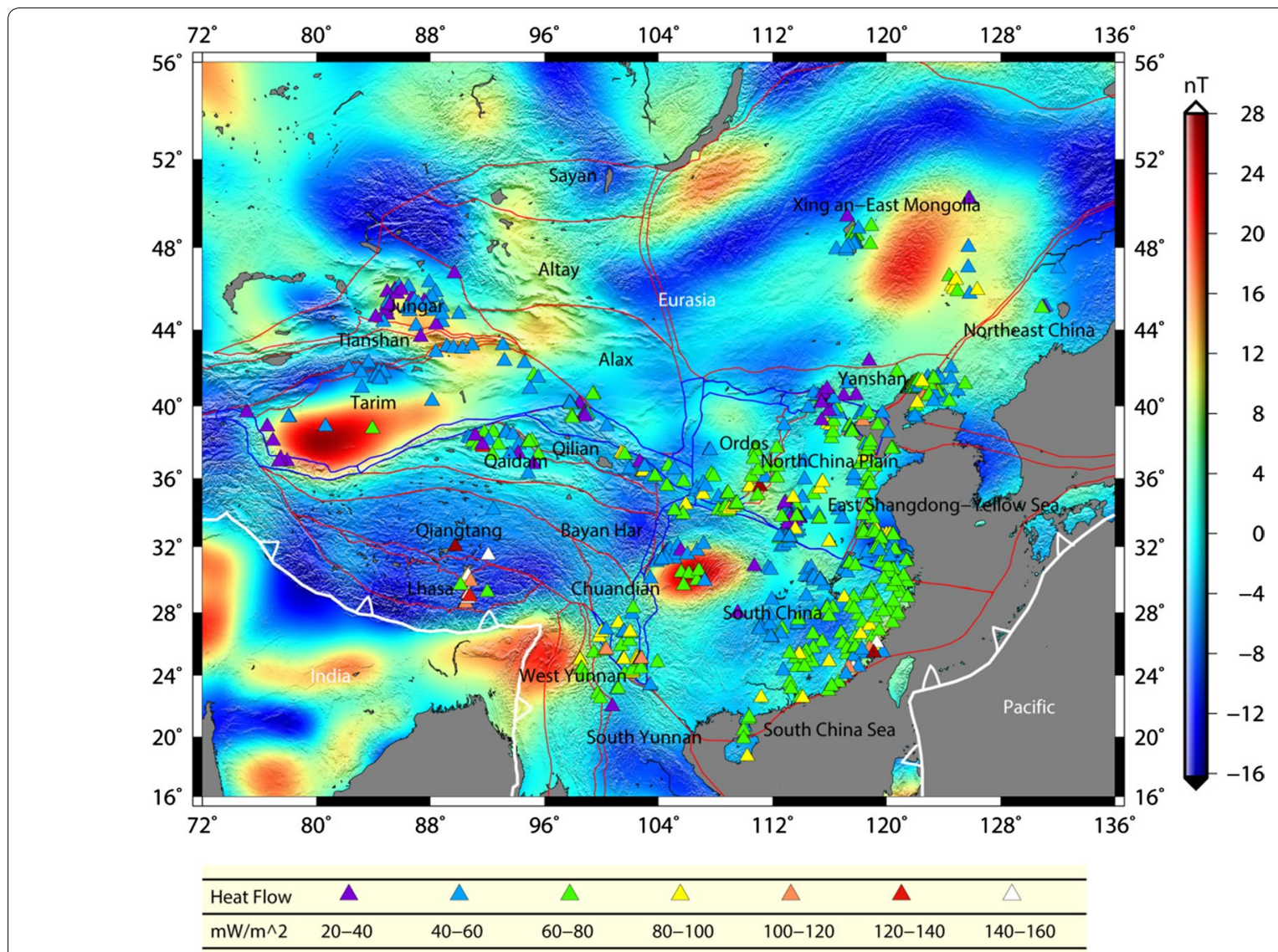

Fig. 9 Comparison of $B_{z}$ (colors) and surface heat flux (triangles). The heat flux data are provided by Hu et al. (2000, 2001). Lines with different colors mark boundaries of different tectonic units (see Figs. 1, 2)

opposite. A magnetic low could come from a shallow Curie isotherm, as well as from a small magnetic susceptibility. In the latter case, it won't bring obvious heat flux. Furthermore, the surface heat flow relates to the Curie isotherm nonlinearly, and other parameters (such as the thermal conductivity, heat production rate, et al.) are also involved, while these won't change the dominate role of Curie depth for LMF in most continental regions.

\section{TESD, a theoretical model}

Enlightened by former studies (e.g. Maule et al. 2005; Kang et al. 2010) and our own comparisons (Fig. 9), we try to explain the correlation between seismicity and magnetic anomalies mainly via the effects of different Curie depths. To invert the Curie depth from satellite magnetic anomalies, equivalent source dipole (ESD) is often adopted for approximation (Mayhew et al. 1980; Purucker et al. 1998, 2002). A center dipole is used in ESD to describe the magnetic field generated by induction of a cuboid block. The susceptibility is assumed to be uniform, and the dipole moment $\mathbf{m}_{\mathrm{I}}$ is proportional to the cuboid volume. The formula is

$$
\mathbf{m}_{\mathrm{I}}=\mathbf{M}_{\mathrm{I}} V=\frac{\kappa \mathbf{B}_{\mathrm{M}}}{\mu_{0}} V
$$

where $\mathbf{M}_{\mathrm{I}}$ is the intensity of magnetization, $V$ is the volume of the cuboid, $\kappa$ is the uniform susceptibility, $\mathbf{B}_{\mathrm{M}}$ is the main field, and $\mu_{0}$ is the permeability of the vacuum. The magnetic field at $\mathbf{r}$ generated by $\mathbf{m}_{\mathrm{I}}$ is

$$
\mathbf{B}_{I}=-\frac{\mu_{0}}{4 \pi r^{3}}\left[\mathbf{m}_{\mathrm{I}}-3\left(\mathbf{m}_{\mathrm{I}} \cdot \hat{\mathbf{r}}\right) \hat{\mathbf{r}}\right]
$$

For simplicity, we set the length and width of the cuboid both at $L$ and considered only the vertical component, ignoring the effects of horizontal magnetization and spherical geometry. The vertical induced field is

$$
B_{I z}=-\frac{\kappa L^{2} d B_{M z}}{2 \pi r^{3}}\left[1-\frac{3(d+H)^{2}}{r^{2}}\right]
$$

where $d$ is the burial depth of the dipole, which is half the height of the cuboid, $B_{M z}$ is the vertical main field, $H$ is 
the altitude (set at $200 \mathrm{~km}$ ), and $r$ is the distance between the source point and the field point.

To explain the correlation between seismicity and the LMF, we put forward a model using two ESDs and labeled it TESD. In our TESD model, as is shown in Fig. 10c, two nearby cuboid blocks are combined, and the magnetic fields are approximated by two dipoles. We checked the distribution characteristics of the magnetic anomaly and compared them with our statistical results.

For simplicity, we assumed the two cuboids both have length and width $L$, but have respective Curie depths of $2 d_{1}$ and $2 d_{2}$. In Fig. 10c, point $\mathrm{A}$ is any point at height $H$ in the same vertical plane with the two dipoles. The horizontal distance between point $\mathrm{A}$ and the dipole center is $h$. The distance $r$ is calculated by

$$
r=\sqrt{h^{2}+(d+H)^{2}}
$$

Parameters are selected as

$$
\begin{gathered}
L=300 \mathrm{~km}, \quad d_{1}=10 \mathrm{~km}, \quad d_{2}=25 \mathrm{~km}, \\
B_{M z}=3 \times 10^{4} \mathrm{nT}, \quad \kappa=0.035 \mathrm{SI}
\end{gathered}
$$

The parameters $\left(d_{1}, d_{2}, B_{M z}\right)$ are selected roughly according to the Tibetan block and the Sichuan basin. The selection of the susceptibility is according to Purucker et al. (2002), Maule et al. (2005), and Rajaram et al. (2009).

In Eq. (3), only the short wavelengths $(\lambda \leq 2500 \mathrm{~km})$ were included in $B_{z}$ for the NGDC-720 model; thus when we compared the magnetic anomaly generated by the TESD model, the long wavelength should also be subtracted. A rigorous study requires that the total magnetic field generated by cuboid 1 and cuboid 2 should be expanded by SHA; then the long wavelength magnetic field of $n=1-15$ is subtracted. The SHA should be done globally, and the Curie depths of areas outside cuboid 1 and cuboid 2 should also be known. These rigorous measures, however, make the computation too complex, so we used a much simpler filter. Instead of the SHA filter, we took the regional longitudinal average. The LMF then became the residual of the total field minus the average field, a process often adopted in analyses of local anomalies.

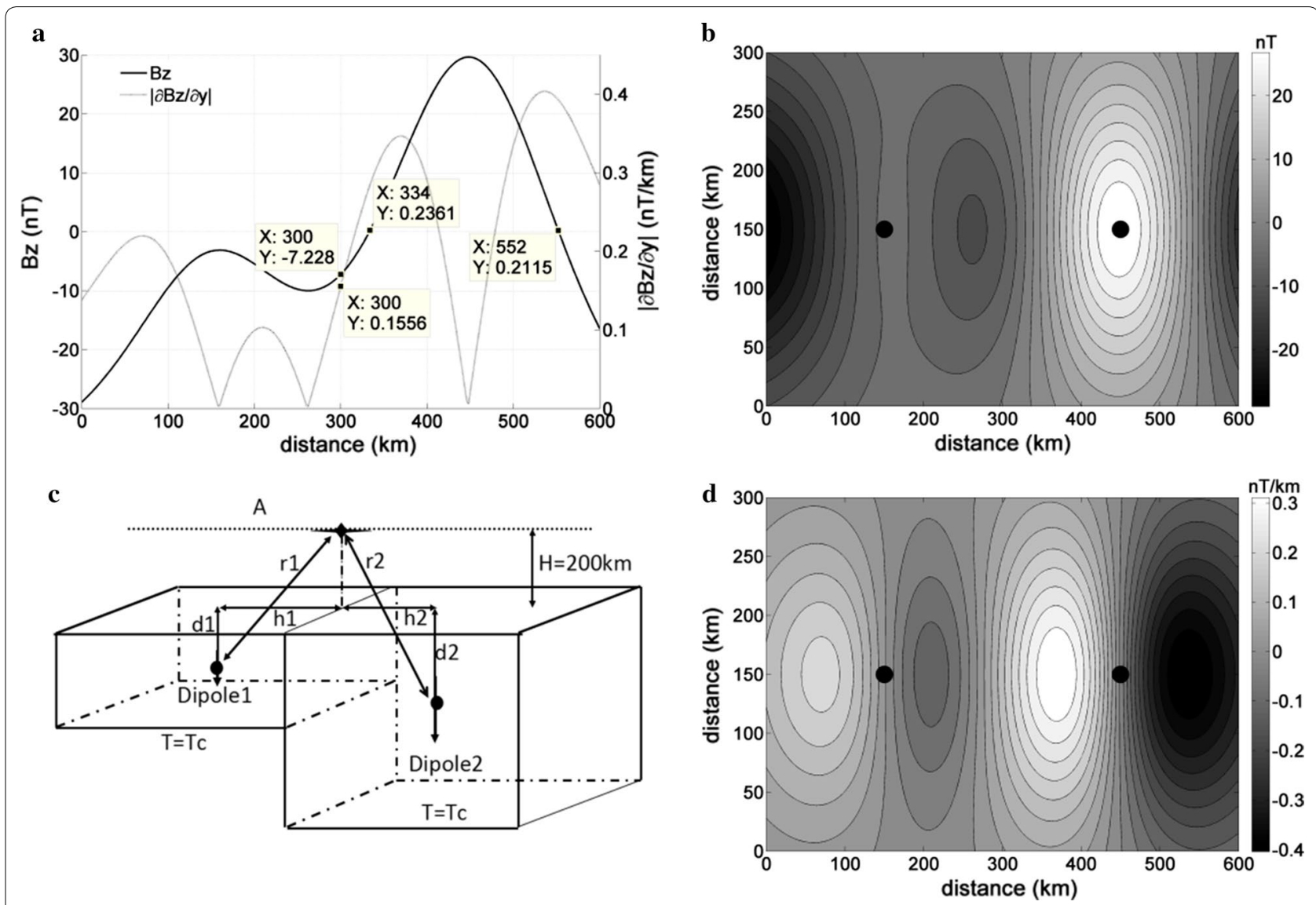

Fig. 10 The TESD (Two Equivalent Source Dipole) model. a $B_{z}$ (solid line) and its $y$-gradient (dashed line, absolute value); $\mathbf{b}$ the distribution of the $2 D$ $B_{z}$. The two black dots are the centers of the two ESD; $\mathbf{c}$ the TESD sketch. The altitude is not in scale; $\mathbf{d}$ the distribution of 2D gradient 
Figure 10a outlines $B_{z}$ and its gradient (the absolute value) when point A moving across the TESD from west to east. Here the gradient is calculated by forward difference. To improve understanding, the $2 \mathrm{D} B_{z}$ and its gradient are also plotted in Fig. 10b, d. The centers of the two ESDs are located at $x=150 \mathrm{~km}$ and $x=450 \mathrm{~km}$, respectively, while the boundary between the two cuboids is located at $x=300 \mathrm{~km}$.

Of the research areas which point A passes through, we derived that $63.5 \%$ are related to negative anomalies (Fig. 10a). We noted that neither $B_{z}$ nor its gradient is zero or maximal at the boundary between the two cuboids. $B_{z}$ has a relatively low negative value $-7.2 \mathrm{nT}$ over the whole research area, varying in magnitude from $-29 \mathrm{nT}$ to $30 \mathrm{nT}$. The gradient is also relatively small $(0.16 \mathrm{nT} / \mathrm{km}$, with a maximum magnitude of $0.40 \mathrm{nT} /$ $\mathrm{km})$. According to our statistical analysis above, the negative anomalies constitute about $52.7 \%$ of the whole area. The magnetic anomaly interval for most earthquake records is -5 to $-3 \mathrm{nT}$ (maximum range for the whole area is -16 to $28 \mathrm{nT}$ ). The magnetic gradient interval is $0.015-0.025 \mathrm{nT} / \mathrm{km}$, with a maximum magnitude of $0.14 \mathrm{nT} / \mathrm{km}$. Although some discrepancies exist between results derived from the TESD model and those from statistical analyses, the ratio $(0.25)$ of the magnetic anomaly on the boundary $(-7.2 \mathrm{nT})$ to the total magnitude $(-29 \mathrm{nT})$ is comparable to our statistical result $(-5 \sim-3 /-16 \approx 0.19-0.31)$. Furthermore, the ratio $(0.25)$ of anomaly gradient on the boundary $(0.16)$ to the largest anomaly gradient $(0.40)$ differs little from our statistical result $(0.015-0.025 / 0.14 \approx 0.11-0.18)$.

The selection of $d_{1}=10 \mathrm{~km}, d_{2}=25 \mathrm{~km}$ corresponds to the Curie depths of $20 \mathrm{~km}$ and $50 \mathrm{~km}$, respectively; thus the bottom temperatures of the two cuboids are both in the Curie isothermal, which is usually set to $580^{\circ} \mathrm{C}$ (Frost and Shive 1986). The resulting temperature difference at the boundary of the two cuboids is remarkable. With a simple linear estimation, the temperature difference will be $348^{\circ} \mathrm{C}$ at the bottom of cuboid 1 . Then differences of parameters directly related to earthquakes or lithospheric dynamics will be evident, such as the effective viscosity (Shi and Cao 2008), defined by:

$$
\eta_{\text {eff }}=\frac{\tau_{\text {creep }}}{\dot{\varepsilon}}=\frac{\dot{\varepsilon}^{\frac{1-n}{n}}}{2 A^{\frac{1}{n}}} \exp \left(\frac{E}{n R T}\right)
$$

in which $\tau_{\text {creep }}$ is the shearing stress for creep deformation, $\dot{\varepsilon}$ is the stain rate, $A, n, E$ are parameters which could be estimated by rock experiments, $R$ is the universal gas constant, and $T$ is the absolute temperature. The influence of the temperature on $\eta_{\text {eff }}$ can be calculated by

$$
\frac{\partial\left(\lg \eta_{\text {eff }}\right)}{\partial T}=-\frac{C}{T^{2}}
$$

Usually we have

$$
C=0.4343 E / n R \approx 4.3 \times 10^{3}
$$

In our TESD model case,

$$
T=580+273=853 \mathrm{~K}, \quad \Delta T=348 \mathrm{~K}
$$

Finally, the computation results in $\eta_{\text {eff } 2}: \eta_{\text {eff1 }} \approx 114$, which means that at the boundary and at a depth of $20 \mathrm{~km}$, the viscosity between the two blocks can be different by a factor of 100 or greater. Note that a remarkable difference of rheology will cause large faults and earthquakes to appear at the boundary (Burov 2007). A viscosity difference of up to two orders of magnitude at a depth of $25 \mathrm{~km}$ between the Tibetan plateau and the Sichuan basin is also supported by other studies (e.g. Shi and Cao 2008; Deng and Tesauro 2016). The possible correlation between Curie depth and earthquakes was formerly presented by other studies (e.g. Rajaram et al. 2009; Gao et al. 2015a, b).

For further study, we also present the magnetic anomaly and its gradient in two dimensions in Fig. 10b, d, where both the magnetic anomaly $(-7.2 \mathrm{nT})$ on line A and its gradient $(0.16 \mathrm{nT} / \mathrm{km})$ are the maximum magnitude for the whole boundary of the two cuboids. The latitude-averaged anomaly is close to $-5 \mathrm{nT}$, and the latitude-averaged anomaly gradient is about $0.1 \mathrm{nT} / \mathrm{km}$ for the whole boundary line. This brings the output of the TESD model even closer to our statistical results.

In addition, we compared the above results with the 2D anomaly $B_{z}$ and its gradient (as shown in Figs. 2, 3, 7) regarding the Tibetan block and the Sichuan basin. The positive anomaly shows many similarities, while the negative anomaly shows differences. This distinction results from the side length of the cuboid not being in scale with the geographical dimensions of the Tibetan block. Moreover, unlike the Sichuan Basin, the Tibet block could not be approached as if it were composed of a single ESD.

\section{Parameter dependence of the TESD model}

During our TESD explanation, we tested only one group of input parameters defined by Formula (11). Various tectonic regions, however, have various parameters. For example, regions near magnetic poles have a larger ambient field $B_{M z}$ and those near the magnetic equators have a smaller $B_{M z}$. In this situation, the magnetic anomaly and its gradient will change in proportional to $B_{M z}$. The anomaly changes in proportional to the magnetic susceptibility also. Therefore, we were more interested in changes in the Curie depth and in the side length. 


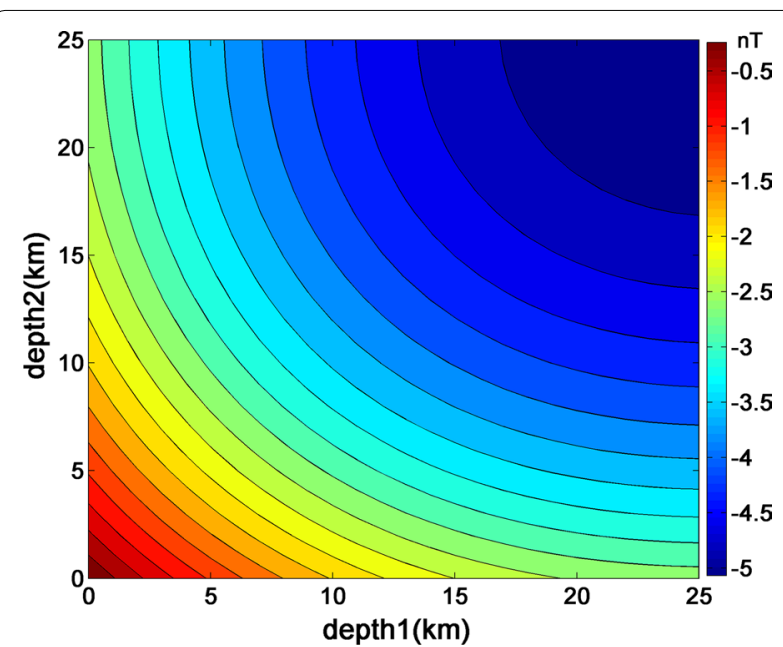

Fig. 11 The averaged boundary anomaly for two nearby blocks with various ESD depths

In Fig. 11 we changed the ESD depths $\left(d_{1}\right.$ and $\left.d_{2}\right)$ and plotted the latitude-averaged boundary magnetic anomaly (at $200 \mathrm{~km}$ altitude) by fixing other parameters as in Formula (11). As Fig. 11 shows, for the parameters selected, the average boundary anomaly is always negative, though not less than $-5 \mathrm{nT}$. For magnetic anomalies between -5 and $-3 \mathrm{nT}$, as was shown in our statistical maximum earthquake span (Fig. 5), an ESD depth difference as large as $10 \mathrm{~km}$ is preferred but not necessary. At least one block with an ESD depth lower than about $15 \mathrm{~km}$ (equivalent to a Curie depth of $30 \mathrm{~km}$ ) is needed to generate the corresponding anomaly.

Next we evaluated the TESD dependence on side length $(L)$ with susceptibilities ranging from $\kappa=0.01$ to $\kappa=0.05$. Similarly, we kept other parameters the same as formula (11). Figure 12 shows the latitude-averaged magnetic anomaly on the boundary, revealing an obvious critical point, before which the average boundary anomaly is always positive and after which that anomaly is always negative. For the parameter selected, the critical side length is $250 \mathrm{~km}$. To get an average anomaly between -5 and $-3 \mathrm{nT}$, the side length of the two blocks must be larger than $250 \mathrm{~km}$, but smaller than a certain value which depends on susceptibility. For example, to make the anomaly larger than $-5 \mathrm{nT}$, the maximum side length for $\kappa=0.04$ is about $300 \mathrm{~km}$. By the same token, however, a larger side length requires a smaller susceptibility.

\section{Conclusions and discussions}

In this study, we compared active tectonics and seismicity to the satellite magnetic anomalies in continental China and surroundings. Our surveys of the distribution of active blocks, faults and GPS movements confirm that

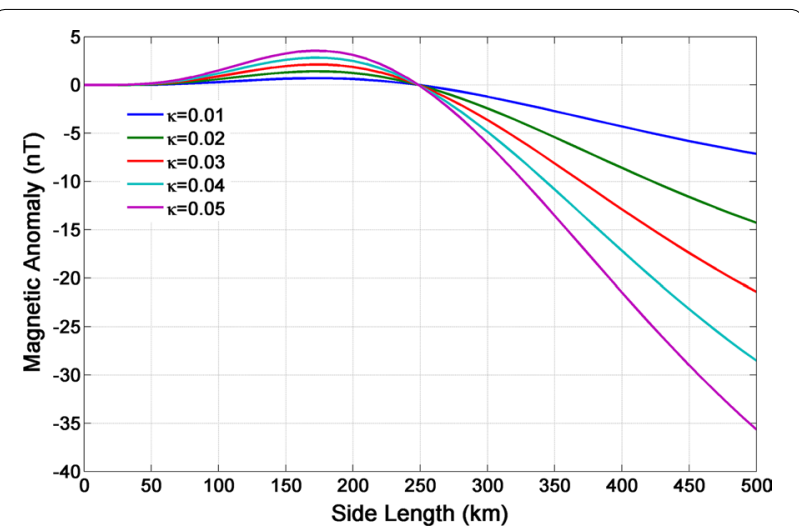

Fig. 12 The averaged boundary anomaly for two nearby blocks with various side lengths and various susceptibilities

the surficial tectonic structures are well reflected by magnetic anomalies measured at high altitudes (Figs. 1, 2, 3). In general, stable cratons and basins showed notable positive anomalies, whereas active orogens exhibited strong negative anomalies. Boundaries of active blocks (i.e. faults) and those of obvious magnetic anomalies often overlap. These phenomena establish a physical foundation for the correlation between seismicity and magnetic anomalies.

Before this study, we usually understood that earthquakes are more likely to occur in areas with zero $B_{z}$, or in high gradient belts. In contrast with these previous understandings, the statistics of this study yielded a consistent correlation between seismicity and $B_{z}$ at $200 \mathrm{~km}$ altitude (Figs. 2, 3, 5, 6). For different time intervals, areas showing $B_{z}$ between -5 and $-3 \mathrm{nT}$ (with a total regional magnitude of -16 to $28 \mathrm{nT}$ ) or areas showing a horizontal gradient (Figs. 7, 8) between 0.015 and $0.025 \mathrm{nT} / \mathrm{km}$ (with a total regional magnitude of $0-0.16 \mathrm{nT} / \mathrm{km}$ ) always revealed seismic susceptibility.

To identify the most suitable parameter among $B_{z}$ and its gradients for constraining seismicity, we intentionally proposed a ratio $q_{\mathrm{EM}}$ to measure the seismic susceptibility. A larger $q_{\mathrm{EM}}$ also corresponds to a higher probability of seismicity. The $q_{\mathrm{EM}}$ for each magnetic anomaly range was calculated (Fig. 6), while the range with most earthquakes is most indicative. By comparing $B_{z}$ and its gradient at various altitudes, we found that seismicity is best constrained by $B_{z}$ at $200 \mathrm{~km}$ (Table 2). The corresponding seismic susceptibility for the period 2004-2007 is 4.7 , which means the probability for earthquakes with $M_{s}>5.0$ occurring in areas with $B_{z}=-5 \sim-3 \mathrm{nT}$ will be 4.7 times that of the statistical average. If $B_{z}$ and its gradient are applied together, they might provide an improved constraint on the spatial distribution of seismicity. 
To explain the correlation between magnetic anomalies and seismicity, we presented a TESD model (Fig. 10). Based on the relation between the Curie isotherm and viscosity, along with our TESD model, we arrived at certain understandings. Most earthquakes tend to occur at the boundary of two distinct blocks with contrasting rheology. The LMF above this boundary does not have to be zero. Instead, because negative anomalies often correlate with active tectonics, the LMF can depart a little from zero toward the negative. Meanwhile, the magnetic anomaly gradient above this boundary can be relatively small or only depart a little from zero. Earthquakes barely occurred in areas with strong positive or strong negative anomalies, because these areas are either too "stiff" (cold) or too "soft" (warm). The parameters selected in the TESD model made an output of magnetic anomaly very close to the statistical result. This set of parameter selection, however, is only one of many possibilities. Other sets of parameters may yield the same or even better outputs. For instance, we checked the parameter dependence of the TESD model (Figs. 11, 12). We found that a Curie depth of at least one block larger than $30 \mathrm{~km}$, and a side length between 250 and $300 \mathrm{~km}$ are needed for the selected ambient vertical main field and susceptibility. For seismically active regions with $B_{z}$ between -5 and $-3 \mathrm{nT}$, an obvious Curie depth difference $(>10 \mathrm{~km})$ for the two nearby blocks is indicated. Yet for seismic inactive regions-also with $B_{z}$ between -5 and $-3 \mathrm{nT}$-the Curie depth difference may be small, but the Curie depth of at least one block must be deeper than some certain value.

Rajaram et al. (2009) found that large magnitude earthquakes are associated with high gradients in Curie depth. For the magnetic anomaly in our study, earthquakes especially those with large magnitudes are associated with the boundaries of obvious anomaly or the boundaries of obvious anomaly gradients. Whether boundaries of obvious anomaly or anomaly gradients coincide with high gradients in Curie depth, however, needs further research. Gao et al. (2015a, b) found that strong earthquakes primarily occurred in areas with the uplift of Curie surface or with shallow Curie surface. Generally, areas with shallow Curie surface exhibit negative anomalies. Our study shows that EQs tend to occur inside areas with negative anomalies (with a percentage of $81.8 \%$ for the year 2004-2007), which is consistent with Gao et al.s results.

It should be noted that different types of activity can't be all simply explained by blocks with contrasting Curie depth. Contrasting stress is also a key factor. GPS measurements, strain rates, diverse sort of focal mechanisms and frequency of seismicity, are all controlled by the stress field and lithosphere strength. A recent study
(Chen et al. 2017) showed that the lithosphere deformation and structures are primarily controlled by the strength heterogeneity of the crust. The lithosphere strength or rheology is affected remarkably by temperature. From this point of view, contrasting viscosity could affect seismic activities to a very large extent.

In the TESD model, the susceptibility $\kappa$ is identical for both blocks. This may not always be true for all adjacent blocks, especially for areas with high heat flux but exhibit a relatively large positive anomaly or vice versa (Fig. 9). In this case (though only a small part of the research area), differences in Curie depth may be small. Different $\kappa$ might also indicate different cuboid compositions, or different types of tectonic blocks, either of which could cause the boundary to be seismically active.

Although 53.2\% of earthquakes have occurred in areas with $B_{z}=-5 \sim-3 \mathrm{nT}$ in the time of 2004-2007, where the probability of seismicity is 4.7 times the statistical average, $46.8 \%$ of moderate and large earthquakes have occurred outside these areas. Possible reasons may lie in different Curie depth distributions, different length scales, anisotropy of susceptibility, or effects of remanence, all of which require further research.

\section{Additional file}

Additional file 1. Supplementary figures for comparisons between Bz and tectonics.

\section{Abbreviations}

LMF: lithosphere magnetic field; TESD: two equivalent source dipole; TMA: transcontinental magnetic anomaly; SHA: spherical harmonic analysis; RTP: reduction to the pole; GPS: global positioning system; ISC: International Seismological Centre.

\section{Authors' contributions}

$L J$ and $Y L$ analyzed the results and drafted the manuscript. $L J$ designed the methodology. HC proposed the research plan. All authors read and approved the final manuscript.

\section{Acknowledgements}

We thank Shi YL and Xu WY for their suggestions on theory, Yang T for many helpful discussions, and David Parks for reviewing the manuscript and editing the English grammar. We thank Hu SB for providing the heat flux data, Deng YF for the viscosity data and Wang $\mathrm{H}$ for the tectonic data. Comments by two anonymous reviewers and the handling editor, $\mathrm{H}$ Oda, substantially improved the manuscript.

\section{Competing interests}

The authors declare that they have no competing interests.

\section{Availability of data and materials}

The Gauss coefficients for calculating $B_{z}$ are from the NGDC-720 model (http:// geomag.org/models/ngdc720.html). For topography data, we used the ETOPO1 model (http://www.ngdc.noaa.gov/mgg/global/global.html). We downloaded seismic records are downloaded from the International Seismological Centre (ISC), On-line Bulletin, http://www.isc.ac.uk. Heat flux data were provided by S. B. Hu, which could also be downloaded from http://www.heatf 
low.und.edu/. We prepared Figs. 1, 2, 3, 4, 7 and 9 by using GMT (Wessel and Smith 1998).

\section{Funding}

This work is funded by National Key R\&D Program of the Ministry of Science and Technology of China with the Project "Integration Platform Construction for Joint Inversion and Interpretation of Integrated Geophysics (Grant No. 2018YFC0603502)," and National Basic Research Program of China "973" (Grant No. 2014CB845906).

\section{Publisher's Note}

Springer Nature remains neutral with regard to jurisdictional claims in published maps and institutional affiliations.

\section{Received: 8 April 2018 Accepted: 1 November 2018} Published online: 16 November 2018

\section{References}

Achache J, Abtout A, Le Mouel JL (1987) The downward continuation of Magsat crustal anomaly field over Southeast Asia. J Geophys Res 92:1158411596. https://doi.org/10.1029/JB092iB11p11584

Alsdorf D, Nelson D (1999) Tibetan satellite magnetic low: evidence for widespread melt in the Tibetan Crust? Geology 27:943-946. https://doi. org/10.1130/0091-7613(1999)0272.3.CO;2

An ZC, Ma SZ, Tan DH (1992) Spherical cap harmonic analysis of satellite magnetic anomaly in China and adjacent region. Chin J Geophys 35(Suppl.):188-197 (in Chinese)

Arkani HJ (2007) Differential reduction to the pole: revisited. Geophysics 72(1):L13-L20. https://doi.org/10.1190/1.2399370

Backus G, Parker R, Constable C (1996) Foundations of geomagnetism. Cambridge University Press, Cambridge, UK

Beroza GC, Kanamori H (2007) Comprehensive overview. In: Schubert G (ed) Earthquake seismology. Treatise on Geophysics, vol 4.01. Elsevier, New York, pp 1-58

Burov EB (2007) Plate rheology and mechanics. In: Schubert G (ed) Crust and lithosphere dynamics. Treatise on Geophysics, vol 6.03. Elsevier, New York, pp 99-151

Chen B, Chen C, Kaban MK, Du JS, Ling Q, Thomas M (2013) Variations of the effective elastic thickness over China and surroundings and their relation to the lithosphere dynamics. Earth Planet Sci Lett 363:61-72. https://doi. org/10.1016/j.epsl.2012.12.022

Chen L, Capitanio FA, Liu LJ, Gerya TV (2017) Crustal rheology controls on the Tibetan plateau formation during India-Asia convergence. Nat Commun 8:15992. https://doi.org/10.1038/ncomms15992

Christensen EF, Lühr H, Hulot G, Haagmans R, Purucker M (2009) Geomagnetic research from space. EOS Trans AGU 90(25):213-214. https://doi. org/10.1029/2009EO250002

Deng YF, Tesauro M (2016) Lithospheric strength variations in Mainland China: tectonic implications. Tectonics 35:1-21. https://doi.org/10.1002/2016T C004272

Deng QD, Zhang PZ, Ran YK, Yang XP, Min W, Chu QZ (2002) Basic characteristics of active tectonics of China. Sci China Earth Sci 46(4):356-372. https:// doi.org/10.1360/03yd9032

Frey H (1982) Magsat scalar anomalies and major tectonic boundaries in Asia. Geophys Res Lett 9(4):299-302. https://doi.org/10.1029/GL009i004p 00299

Frost BR, Shive PN (1986) Magnetic mineralogy of the lower continental crust. J Geophys Res 91(B6):6513-6521. https://doi.org/10.1029/JB091iB06p 06513

Gao GM, Kang GF, Bai CH, Li GQ (2013) Distribution of the crustal magnetic anomaly and geological structure in Xinjiang, China. J Asian Earth Sci 77:12-20. https://doi.org/10.1016/j.jseaes.2013.08.014

Gao GM, Kang GF, Bai CH, Wen LM (2015a) Study on crustal magnetic anomalies and Curie surface in Southeast Tibet. J Asian Earth Sci 97:169-177. https://doi.org/10.1016/j.jseaes.2014.10.035

Gao GM, Kang GF, Li GQ, Bai CH (2015b) Crustal magnetic anomaly in the Ordos region and its tectonic implications. J Asian Earth Sci 109:63-73. https://doi.org/10.1016/j.jseaes.2015.04.033
Han P, Huang QH, Xiu JG (2009) Principal component analysis of geomagnetic diurnal variation associated with earthquakes: case study of the M6.1 Iwate-ken Nairiku Hokubu earthquake. Chin J Geophys 52(6):1556-1563. https://doi.org/10.3969/j.issn.00015733.2009.06.017 (in Chinese)

Hu SB, He LJ, Wang JY (2000) Heat flow in the continental area of China: a new data set. Earth Planet Sci Lett 179:407-419. https://doi.org/10.1016/S0012 $-821 \times(00) 00126-6$

Hu SB, He LJ, Wang JY (2001) Complilation of heat flow data in the China continental area (3rd edition). Chin J Geophys 44(5):611-626. https://doi. org/10.1002/cjg2.180 (in Chinese)

Huang QH (2011) Retrospective investigation of geophysical data possibly associated with the Ms8.0 Wenchuan earthquake in Sichuan, China. J Asian Earth Sci 41(4-5):421-427. https://doi.org/10.1016/j.jseae s.2010.05.014

James EY, Richard C, James N (1976) Seismicity and quaternary faulting in China. Bull Seismol Soc Am 66(6):1983-2001

Jiao LG, Chen HR, Gao MT (2013) Magnetic constraints on the spatial distribution of seismicity. Earthq Sci 26(2):125-136. https://doi.org/10.1007/s1158 9-013-0022-3

Johnston MJS (1997) Review of electric and magnetic fields accompanying seismic and volcanic activity. Surv Geophys 18(5):441-475. https://doi. org/10.1023/A:1006500408086

Kang GF, Gao GM, Bai CH, Wang J, Shao D (2010) Distribution of the magnetic anomaly for the CHAMP satellite in China and adjacent areas. Chin J Geophys 53(4):895-903. https://doi.org/10.3969/j.issn.00015733.2010.04.014 (in Chinese)

Kang GF, Gao GM, Bai CH, Shao D, Feng LL (2012) Characteristics of the crustal magnetic anomaly and regional tectonics in the Qinghai-Tibet Plateau and the adjacent areas. Sci China Earth Sci 55(6):1028-1036. https://doi. org/10.1007/s11430-011-4323-X

Kang GF, Gao GM, Bai CH, Wang TY, Wang YM, Zhu T (2013) Study on distribution features of crustal magnetic anomalies around eastern Himalayan syntaxis. Chin J Geophys 56(6):731-741. https://doi.org/10.1002/ cjg2.20066

Kolmogorov A (1933) Sulla determinazione empirica di una legge di distribuzione. G Ist Ital Attuari 4:83-91

Kruskal WH, Wallis WA (1952) Use of ranks in one-criterion variance analysis. J Am Stat Assoc 47(260):583-621. https://doi.org/10.1080/01621 459.1952.10483441

Langel RA, Hinze WJ (1998) The magnetic field of the Earth's lithosphere-the satellite perspective. Cambridge University Press, Oxford. https://doi. org/10.1016/S0273-1177(99)00963-1

Mann HB, Whitney DR (1947) On a test of whether one of two random variables is stochastically larger than the other. Ann Math Stat 18(1):50-60. https://doi.org/10.1214/aoms/1177730491

Marianna B, Vincenzo L, Gerardo R, Agata S, Tony AS, Luciano T (2014) Electric and magnetic field changes observed during a seismic swarm in Pollino Area (Southern Italy). Bull Seismol Soc Am 104(3):1289-1298. https://doi. org/10.1785/0120130183

Maule CF, Purucker ME, Olsen N, Mosegaard K (2005) Heat flux anomalies in Antarctica revealed by satellite magnetic data. Science 309:464-467. https://doi.org/10.1126/science. 1106888

Maus S (2010) An ellipsoidal harmonic representation of Earth's lithospheric magnetic field to degree and order 720. Geochem Geophys Geosyst 11 (6):Q06015. https://doi.org/10.1029/2010GC003026

Maus S, Yin F, Lühr H, Manoj C, Rother M, Rauberg J, Michaelis I, Stolle C, Müller RD (2008) Resolution of direction of oceanic magnetic lineations by the sixth-generation lithospheric magnetic field model from CHAMP satellite magnetic measurements. Geochem Geophys Geosyst 9(7):Q07021. https ://doi.org/10.1029/2008GC001949

Maus S, Barckhausen U, Berkenbosch H, Bournas N, Brozena J, Childers V, Dostaler F, Fairhead JD, Finn C, von Frese RRB, Gaina C, Golynsky S, Kucks R, Lühr H, Milligan P, Mogren S, Müller RD, Olesen O, Pilkington M, Saltus R, Schreckenberger B, Thébault E, Tontini FC (2009) EMAG2: a 2-arc min resolution Earth Magnetic Anomaly Grid compiled from satellite, airborne, and marine magnetic measurements. Geochem Geophys Geosyst 10(8):Q08005. https://doi.org/10.1029/2009GC002471

Mayhew MA, Johnson BD, Langel RA (1980) An equivalent source model of the satellite-altitude magnetic anomaly field over Australia. Earth Planet Sci Lett 51(1):189-198. https://doi.org/10.1016/0012-821X(80)90266-6 
Mitsui Y, Yamada K (2017) Possible correlation between annual gravity change and shallow background seismicity rate at subduction zone by surface load. Earth Planets Space 69:166. https://doi.org/10.1186/s4062 3-017-0753-9

Olsen N, Hulot G, Sabaka TJ (2007) The present field. In: Schubert G (ed) Geomagnetism. Treatise on geophysics, vol 5.02. Elsevier, New York, pp 33-72

Olsen N, Christopher CF, Stavros K, Lars TC (2016) A model of Earth's magnetic field derived from 2 years of Swarm satellite constellation data. Earth Planets Space 68:124-133. https://doi.org/10.1186/s40623-016-0488-z

Purucker ME, Langel RA, Rajaram M, Raymond C (1998) Global magnetization models with a priori information. J Geophys Res 103(B2):2563-2584. https ://doi.org/10.1029/97JB02935

Purucker ME, Langlais B, Olsen N, Hulot G, Mandea M (2002) The southern edge of cratonic North America: evidence from new satellite magnetometer observations. Geophys Res Lett 29(15):1-4. https://doi. org/10.1029/2001GL013645

Rajaram M, Anand SP, Hemant K, Purucker ME (2009) Curie isotherm map of Indian subcontinent from satellite and aeromagnetic data. Earth Planet Sci Lett 281(3-4):147-158. https://doi.org/10.1016/j.epsl.2009.02.013

Robert M, John WT, Wayne AL (1978) Variation of box plots. Am Stat 32(1):1216. https://doi.org/10.2307/2683468

Sabaka TJ, Olsen N, Purucker ME (2004) Extending comprehensive models of the Earth's magnetic field with Ørsted and CHAMP data. Geophys J Int 159(2):521-547. https://doi.org/10.1111/j.1365-246X.2004.02421.x

Shi YL, Cao JL (2008) Effective viscosity of China continental lithosphere. Earth Sci Front 15(3):82-95. https://doi.org/10.1016/S1872-5791(08)60064-0

Smirnov N (1948) Table for estimating the goodness of fit of empirical distributions. Ann Math Stat 19:279-281. https://doi.org/10.1214/aoms/11777 30256

Stuart WD, Banks PO, Sasai Y, Liu SW (1995) Piezomagnetic field for Parkfield fault model. J Geophys Res Atmos 1002:24101-24110. https://doi. org/10.1029/95JB02516

Taylor PT, Kim RH, Kutina J, Johnson GL (2008) Geohazard assessment from satellite magnetic data modeling with examples from the Arctic Margin along the Canada Basin and the Korean Peninsula along $40 \mathrm{~N}$ (latitude) parallel. Earth Planets Space 60(5):497-503. https://doi.org/10.1186/ BF03352816

Thébault E, Purucker ME, Whaler KA, Langlais B, Sabaka TJ (2010) The magnetic field of Earth's lithosphere. Space Sci Rev 155:95-127. https://doi. org/10.1007/s11214-010-9667-6

von Frese RRB, Kim JW, Hernandez O, Kim HR, Asgharzadeh MF (2008) Assessing intraplate earthquake hazards from satellite geopotential field observations. Earth Planets Space 60(5):487-495. https://doi.org/10.1186/ BF03352815

Wang Q, Zhang PZ, Freymueller JT, Bilham R, Larson KM, Lai XA, You XZ, Niu ZJ, Wu JC, Li YX, Liu JN, Yang ZQ, Chen QZ (2001) Present-day crustal deformation in China constrained by global positioning system measurements. Science 294:574-577. https://doi.org/10.1126/science.1063647
Wang HL, Chen C, Zhang CD (2008) Some knowledge about the latest lithospheric magnetic field models and characters of magnetic anomalies for China. Earth Sci Front 15(3):64-71

Wei RQ, Yu L (2012) Constraints from satellite crustal magnetic field on the distribution of the epicenters for earthquakes in the continental crust of China. Chin J Geophys 55(8):2643-2650. https://doi.org/10.6038/j. issn.00015733.2012.08.016 (in Chinese)

Wesnousky SG, Jones L, Scholz CH (1984) Historical seismicity and rates of crustal deformation along the margins of the Ordos block, North China. Bull Seismol Soc Am 74(5):1767-1783

Wessel P, Smith WHF (1998) New improved version of the generic mapping tools released. EOS Trans AGU 79:579. https://doi.org/10.1029/98EO00426

Xu YF (1997) A crustal magnetization model and Curie isothem. Acta Geophys $\operatorname{Sin}$ 40(4):481-486

Xu YF, An ZC, Huang BC, Golovkov VP, Rotanova NM, Kharitonov AL (2000) The apparent magnetization of Asia. Sci China Earth Sci 43(6):654-660. https ://doi.org/10.1007/BF02879510

Zhang PZ, Deng QD, Zhang GM, Ma J, Gan WJ, Min W, Mao FY, Wang Q (2003) Active tectonic blocks and strong earthquakes in the continent of China. Sci China Earth Sci 46(z2):13-24. https://doi.org/10.3969/j.issn.16747313.2003.z2.002

Zhang GM, Ma HS, Wang H, Li L (2004a) Correlation between active blocks and strong seismic activities in Mainland China. Sci China Earth Sci 34(7):591-599

Zhang PZ, Shen ZK, Wang M, Gan WJ, Burgmann R, Molnar P, Wang Q, Niu ZJ, Sun JZ, Wu JC, Sun HR, You XZ (2004b) Continuous deformation of the Tibetan Plateau from global positioning system data. Geology 32(9):809-812. https://doi.org/10.1130/G20554.1

Zhang GM, Ma HS, Wang H, Wang XL (2005) Boundaries between active-tectonic blocks and strong earthquakes in China Mainland. Chin J Geophys 48(3):602-610. https://doi.org/10.1002/cjg2.699 (in Chinese)

Zhang JS, Gao R, Zeng LS, Li QS, Guan Y, He RZ, Wang HY, Lu ZW (2010) Relationship between characteristics of gravity and magnetic anomalies and the earthquakes in the Longmenshan range and adjacent areas. Tectonophysics 491:218-229. https://doi.org/10.1016/j.tecto.2009.12.004

Zhang JG, Jiao LG, Liu XC, Ma XX (2013) A study on the characteristics of ULF electromagnetic spectrum before and after the Wenchuan Ms8.0 earthquake. Chin J Geophys 56(4):1253-1261. https://doi.org/10.6038/cjg20 130420 (in Chinese)

Zhao DP, Yu S, Ohtani E (2011) East Asia: seismotectonics, magmatism and mantle dynamics. J Asian Earth Sci 40:689-709. https://doi.org/10.1016/j. jseaes.2010.11.013

Zhu RX, Xu YG, Zhu G, Zhang HF, Xia QK, Zheng TY (2012) Destruction of the North China Craton. Sci China Earth Sci 55(10):1565-1587. https://doi. org/10.1007/s11430-012-4516-y

\section{Submit your manuscript to a SpringerOpen ${ }^{\odot}$ journal and benefit from:}

- Convenient online submission

- Rigorous peer review

- Open access: articles freely available online

- High visibility within the field

- Retaining the copyright to your article

Submit your next manuscript at springeropen.com 